\title{
Enhanced PRL-1 expression in placenta- derived mesenchymal stem cells accelerates hepatic function via mitochondrial dynamics in a cirrhotic rat model
}

\author{
Jae Yeon Kim', Jong Ho Choi², Ji Hye Jun', Sohae Park', Jieun Jung ${ }^{1}$, Si Hyun Bae ${ }^{3}$ and Gi Jin Kim ${ }^{1 *}$ (D)
}

\begin{abstract}
Background: Placenta-derived mesenchymal stem cells (PD-MSCs) have been highlighted as an alternative cell therapy agent that has become a next-generation stem cell treatment. Phosphatase of regenerating liver-1 (PRL-1), an immediate early gene, plays a critical role during liver regeneration. Here, we generated enhanced PRL-1 in PDMSCs (PD-MSCS ${ }^{\text {PRL-1 }}$, PRL-1+) using lentiviral and nonviral gene delivery systems and investigated mitochondrial functions by PD-MSC ${ }^{\text {PRL-1 }}$ transplantation for hepatic functions in a rat bile duct ligation (BDL) model.

Methods: PD-MSCS ${ }^{\text {PRL-1 }}$ were generated by lentiviral and nonviral AMAXA gene delivery systems and analyzed for their characteristics and mitochondrial metabolic functions. Liver cirrhosis was induced in Sprague-Dawley (SD) rats using common BDL for 10 days. PKH67+ naïve and PD-MSCs ${ }^{\text {PRL-1 }}$ using a nonviral sysyem $\left(2 \times 10^{6}\right.$ cells/animal) were intravenously administered into cirrhotic rats. The animals were sacrificed at 1, 2, 3, and 5 weeks after transplantation and engraftment of stem cells, and histopathological analysis and hepatic mitochondrial functions were performed.

Results: PD-MSCS ${ }^{\text {PRL-1 }}$ were successfully generated using lentiviral and nonviral AMAXA systems and maintained characteristics similar to those of naive cells. Compared with naïve cells, PD-MSCs ${ }^{\text {PRL-1 }}$ improved respirational metabolic states of mitochondria. In particular, mitochondria in PD-MSCs ${ }^{\text {PRL-1 }}$ generated by the nonviral AMAXA system showed a significant increase in the respirational metabolic state, including ATP production and mitochondrial biogenesis $\left({ }^{*} p<\right.$ 0.05). Furthermore, transplantation of PD-MSCs ${ }^{\text {PL-1 }}$ using a nonviral AMAXA system promoted engraftment into injured target liver tissues of a rat BDL cirrhotic model and enhanced the metabolism of mitochondria via increased mtDNA and ATP production, thereby improving therapeutic efficacy.

Conclusions: Our findings will further our understanding of the therapeutic mechanism of enhanced MSCs and provide useful data for the development of next-generation MSC-based cell therapy and therapeutic strategies for regenerative medicine in liver disease.
\end{abstract}

Keywords: Chronic liver fibrosis, Mitochondria, Phosphatase of regenerating liver-1, Placenta-derived mesenchymal stem cells

\footnotetext{
* Correspondence: gjkim@cha.ac.kr

'Department of Biomedical Science, CHA University, Seongnam 13488, Republic of Korea

Full list of author information is available at the end of the article
}

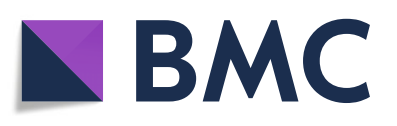

(- The Author(s). 2020 Open Access This article is licensed under a Creative Commons Attribution 4.0 International License, which permits use, sharing, adaptation, distribution and reproduction in any medium or format, as long as you give appropriate credit to the original author(s) and the source, provide a link to the Creative Commons licence, and indicate if changes were made. The images or other third party material in this article are included in the article's Creative Commons licence, unless indicated otherwise in a credit line to the material. If material is not included in the article's Creative Commons licence and your intended use is not permitted by statutory regulation or exceeds the permitted use, you will need to obtain permission directly from the copyright holder. To view a copy of this licence, visit http://creativecommons.org/licenses/by/4.0/. The Creative Commons Public Domain Dedication waiver (http://creativecommons.org/publicdomain/zero/1.0/) applies to the data made available in this article, unless otherwise stated in a credit line to the data. 


\section{Introduction}

Regenerative medicine using stem cells is a new promising field for treating damaged organs and various degenerative diseases, such as difficult-to-treat hepatic failure disease. Various stem cells have the capacity to ameliorate liver damage in animal models of hepatic failure. Chronic liver disease is characterized by permanent changes to the liver and is associated with poor outcomes and high mortality. Although the most effective therapy for acute hepatic failure and advanced cirrhosis is liver transplantation, this procedure has several limitations, including surgical complications, immunological suppression, and high medical cost [1].

The function of mitochondria in the liver following hepatic failure is important for liver regeneration [2]. Hepatic diseases cause defects in mitochondrial structure and function, as the mitochondria in the hepatocytes of patients with nonalcoholic steatohepatitis are swollen and exhibit abnormal morphology with a loss of cristae; additionally, in these patients, the activities of mitochondrial respiratory complexes are impaired, and mitochondrial oxidative stress is increased [3, 4]. Moreover, the dynamics of mitochondrial biogenesis are essential to liver regeneration [5]. Augmentation of liver regeneration knockdown inhibits mitochondrial transcription factor A (mtTFA) and peroxisome proliferatoractivated receptor gamma coactivator-1 alpha (PGC-1 $\alpha$ ), resulting in impaired mitochondrial biogenesis [6].

In hepatic failure diseases, hepatic restoration by bone marrow-derived mesenchymal stem cell (BM-MSC) transplantation is associated with the mitochondriadependent pathway [7]. The therapeutic action of MSCs in liver disease has been postulated to include differentiation into hepatocytes or fusion with endogenous hepatocytes [8]. MSCs reduce liver injury by ameliorating oxidative stress through the release of antioxidants and antifibrotic effects [9]. Recently, autologous MSC transplantation into patients with hepatic diseases was attempted in clinical trials [10, 11]. Clinical trials have shown that BM-MSC transfusion can improve hepatic function [12]. Although hepatic function tests were improved in several patients, the trial triggered side effects [13]. In particular, isolation of autologous MSCs in patients has limitations, including pain and a lack of fresh MSCs harvested from patients.

Placenta-derived mesenchymal stem cells (PD-MSCs) have very strong immune-modulatory privileges [14]. Recently, we reported that increased autophagy induced by PD-MSC transplantation promotes hepatic regeneration in carbon tetrachloride $\left(\mathrm{CCl}_{4}\right)$-induced hepatic cirrhotic rats [15]. In addition, epigenetic alterations induced by PD-MSCs through the interleukin-6 (IL-6)/ signal transducer and activator of transcription 3 (STAT3) signaling pathway improve liver regeneration
[16]. Moreover, human placental MSC administration significantly decreased transforming growth factor- $\beta 1$ and alpha smooth muscle actin expression and enhanced liver function in $\mathrm{CCl}_{4}$-induced fibrotic rats [17].

Phosphatase of regenerating liver-1 (PRL-1), a protein tyrosine phosphatase, was originally identified as an immediate early gene in liver regeneration [18]. The function of PRL-1 is to promote cell migration and invasion by stimulating matrix metalloproteinase (MMP)-2 and MMP-9 expression via the Src kinase and ERK1/2 pathways; additionally, PRL-1 binds to p115 Rho GTPaseactivating protein $[19,20]$. Ectopic expression of PRL-1 increases Rho levels, which have a critical role in actin filament assembly and focal adherin stabilization [21]. PRL-1 expression protects cells from apoptosis and is essential for the normal timing of cell cycle progression during liver regeneration [22]. Moreover, PRL-1 regulates hematopoietic stem cell behavior [23, 24].

However, the effect of enhanced PRL-1 expression in PD-MSCs (PD-MSCs ${ }^{\text {PRL-1 }}$, PRL-1+) on mitochondrial function properties in hepatic cirrhotic liver remains unclear. Therefore, the objective of this study is to generate stable PD-MSCs ${ }^{\text {PRL-1 }}$ using lentiviral and nonviral systems, compare their characteristics, and demonstrate their therapeutic effects on liver function through the mitochondrial metabolic pathway in a rat cirrhosis model established by bile duct ligation (BDL).

\section{Materials and methods}

\section{Cell culture}

Placentas at term ( $\geq 37$ gestational weeks) were assembled from women without medical, obstetrical, and surgical complications. The collection of samples and their use for research purposes were approved by the Institutional Review Board (IRB) of CHA General Hospital, Seoul, Korea (IRB 07-18). All participating women provided written, informed consent. PD-MSCs were harvested as previously described [25]. PD-MSCs were maintained in alpha-modified minimal essential medium ( $\alpha$-MEM; HyClone, Logan, UT, USA) supplemented with 10\% fetal bovine serum (FBS; Gibco, Carlsbad, CA, USA), $1 \%$ penicillin/streptomycin (P/S; Gibco), $25 \mathrm{ng} / \mathrm{ml}$ human fibroblast growth factor-4 (hFGF-4) (PeproTech, Rocky Hill, NJ, USA), and $1 \mu \mathrm{g} / \mathrm{ml}$ heparin (Sigma-Aldrich, St. Louis, MO, USA). Primary hepatocytes from 7 week-old male Sprague-Dawley (SD) rats (Orient Bio Inc., Seongnam, Korea) were isolated using a two-step collagenase perfusion process and were cultured in William's E medium (Sigma-Aldrich) supplemented with 10\% FBS (Gibco), 1\% P/S (Gibco), and $4 \mathrm{mML}$-glutamine (Gibco). To induce cholestatic injury in primary hepatocytes, $100 \mu \mathrm{M}$ lithocholic acid (LCA) was applied for $12 \mathrm{~h}$. Naïve and PD-MSCs ${ }^{\text {PRL-1 }}\left(1 \times 10^{5}\right.$ cells $)$ were seeded onto Transwell inserts $(8-\mu \mathrm{m}$ pore size; Corning, 
NY, USA). Cells were maintained at $37{ }^{\circ} \mathrm{C}$ in a humidified atmosphere containing $5 \% \mathrm{CO}_{2}$.

\section{Gene transfections}

The PRL-1 plasmid (human protein tyrosine phosphatase type 4 A, member 1; PTP4A1) was purchased (Origene Inc., Rockville, MD, USA) and used to induce the overexpression of the PRL-1 gene. The CMV6-AC vector containing PRL-1, the GFP reporter gene, CMV promoters, and the antibiotic neomycin was digested with Sgf1 and Mlu1 restriction enzymes. The PRL-1 lentiviral plasmid was purchased from SeouLin Bioscience (Seongnam, Korea). The pLenti-RSV-EF1 $\alpha$ vector including PRL-1 was constructed with a C-terminal GFP as well as the antibiotic puromycin. The AMAXA pCMV-GFP vector was obtained from Lonza (Basel, Switzerland). The resulting plasmid was confirmed by DNA sequencing. Naïve PDMSCs $\left(6 \times 10^{4}\right.$ cells $\left./ \mathrm{cm}^{2}\right)$ were harvested and transfected by using an AMAXA system with a Human MSC Nucleofector Kit (Lonza) and lentiviral vector (SeouLin Bioscience). After transfections by each system, cells generated using AMAXA were selected by using $1.5 \mathrm{mg} /$ $\mathrm{ml}$ neomycin. In addition, cells generated using lentiviral vector were selected by using $2 \mu \mathrm{g} / \mathrm{ml}$ puromycin for 7 days. We changed the medium every other day and observed changes in cell morphology. Cells were maintained at $37^{\circ} \mathrm{C}$ in a humidified atmosphere containing $5 \% \mathrm{CO}_{2}$.

\section{Animal models and transplantation of MSCs}

Seven-week-old male SD rats (Orient Bio Inc.) were housed under specific pathogen-free conditions. Liver cirrhosis was induced by common BDL as previously described [26]. Naïve cells (TTx naïve; $n=20$ ) and PDMSCs $^{\text {PRL-1 }}$ (TTx PRL-1+; $\left.n=20\right)\left(2 \times 10^{6}\right.$ cells, 9-10 passages) were stained with the PKH67 Fluorescent Cell Linker Kit (Sigma-Aldrich) and transplanted through the tail vein. Nontransplanted (NTx; $n=20)$ rats were maintained as well as sham controls (Con; $n=5)$. After 1,2 , 3 , and 5 weeks, the rats were sacrificed, and their liver tissues and blood were harvested. Alanine aminotransferase (ALT), aspartate aminotransferase (AST), total bilirubin (TBIL), and albumin levels were measured using separated serum from the blood (Southeast MediChem Institute, Busan, Korea). In all animal experimental processes, protocols were approved by the Institutional Animal Care Use Committee (IACUC) of CHA University, Seongnam, Korea (IACUC-180023).

\section{Histopathological and immunofluorescence analysis}

To confirm the induction of liver cirrhosis with BDL and engraftment into target injured tissue for histological examination, liver specimens for each group $(n=$ 5) were collected and fixed in $10 \%$ neutral buffered formalin (NBF). Samples were embedded in paraffin and
OCT compound and processed as 5 - $\mu$ m-thick sections for hematoxylin and eosin (H\&E), Sirius red, Masson's trichrome, and PKH67+ (green) staining. 4',6-Diamidino-2-phenylindole (DAPI) (Invitrogen, Carlsbad, CA, USA) was used as a counterstain for immunofluorescence. Morphometric images of whole sections in the liver were captured using a digital slide scanner (3DHISTECH Ltd., Budapest, Hungary).

\section{Reverse transcription and quantitative real-time polymerase chain reaction (PCR) analysis}

Total RNA was extracted from samples with TRIzol LS Reagent (Invitrogen). cDNA was synthesized by reverse transcription from total RNA (500 ng) using SuperScript III reverse transcriptase (Invitrogen) according to the manufacturer's instructions. To analyze stemness and hepatogenic differentiation markers of naïve and PDMSCs ${ }^{\text {PRL-1 }}$, PCR amplification was performed with specific primers (Table 1, designed by BIONEER, Daejeon, Korea). $\beta$-actin was used as an internal control.

To assess the differentiation, migration, mitochondrial biogenesis, and albumin expression of samples, qRT-PCR was performed with human and rat primers (Tables 2 and 3, designed by BIONEER) and SYBR Green Master Mix (Roche, Basel, Switzerland) in a CFX Connect ${ }^{\text {tw }}$ Real-Time System (Bio-Rad, Hercules, CA, USA). Target gene expression was normalized to GAPDH, and the $2-\Delta \Delta C T$ method generated the relative values of mRNA expression. All reactions were performed in triplicate.

\section{Western blotting}

To assess the specific gene expression of PD-MSCs ${ }^{\text {PRL-1 }}$ and cirrhotic liver tissues, samples were lysed in protein lysis buffer (Sigma-Aldrich). The protein lysates were loaded on sodium dodecyl sulfate polyacrylamide gels, and separated proteins were transferred to PVDF membranes. The following primary antibodies were used: anti-human PRL-1, anti-Oct4 (1:1000; all from Abcam, Cambridge, UK), anti-albumin, anti-HLA-G (4 h84) (1: 1000; all from Novus Biologicals, Littleton, CO, USA), anti-ATP5B (1:200; Santa Cruz Biotechnology, Dallas, TX, USA), anti-ROCK1, anti-RhoA, anti-CDK4, anticyclin D1, and mitochondrial marker antibody sampler kit (1:1000; all from Cell Signaling Technology, Denvers, MA, USA). The loading control was anti-GAPDH (1: 3000; AbFrontier, Seoul, Korea). The following secondary antibodies were used: anti-mouse IgG (1:5000; BioRad, Hercules, CA, USA) and anti-rabbit IgG (1:10,000; Bio-Rad). The bands were detected using ECL reagent (Bio-Rad).

\section{Multilineage differentiation analysis}

To induce adipogenic and osteogenic differentiation, PDMSCs $^{\text {PRL-1 }}$ (5 passages) generated using lentiviral and 
Table 1 Primer sequences using reverse transcription polymerase chain reaction

\begin{tabular}{|c|c|c|c|}
\hline Genes & & Primer sequences & $\mathrm{Tm}$ \\
\hline \multirow[t]{2}{*}{ Oct4 } & Forward & 5'-AGTGAGAGGCAACCTGGAGA-3' & 52 \\
\hline & Reverse & 5'-GTGAAGTGAGGGCTCCCATA-3' & \\
\hline \multirow[t]{2}{*}{ Nanog } & Forward & 5'-TTCTTGACTGGGACCTTGTC-3' & 52 \\
\hline & Reverse & 5'-GCTTGCCTTGCTTTGAAGCA-3' & \\
\hline \multirow[t]{2}{*}{ Sox2 } & Forward & 5'-GGGCAGCGTGTACTTATCCT-3' & 52 \\
\hline & Reverse & 5'-AGAACCCCAAGATGCACAAC-3' & \\
\hline \multirow[t]{2}{*}{ HLA-G } & Forward & 5'-GCGGCTACTACAACCAGAGC-3' & 58 \\
\hline & Reverse & 5'-GCACATGGCACGTGTATCTC-3' & \\
\hline \multirow[t]{2}{*}{ TERT } & Forward & 5'-GAGCTGACGTGGAAGATGAG-3' & 55 \\
\hline & Reverse & 5'-CTTCAAGTGCTGTCTGATTCCAATG-3' & \\
\hline \multirow[t]{2}{*}{ Albumin } & Forward & 5'-TGAGTTTGCAGAAGTTTCCA-3' & 60 \\
\hline & Reverse & 5'-CCTTGCCTCAGCATAGTTT-3' & \\
\hline \multirow[t]{2}{*}{ TAT } & Forward & 5'-AACGATGTGGAGTTCACGG-3' & 55 \\
\hline & Reverse & 5'-GACACATCCTCAGGAGAATGG-3' & \\
\hline \multirow[t]{2}{*}{ HNF1A } & Forward & 5'-TACACCACTCTGGCAGCCACACT-3' & 60 \\
\hline & Reverse & 5'-CGGTGGGTACATACCTGACAGAAC-3' & \\
\hline \multirow[t]{2}{*}{ CYP2B6 } & Forward & 5'-CTTGACCTGCTGCTTCTTCC-3' & 55 \\
\hline & Reverse & 5'-TGCTTCCCGCCTCAGATTTCTC-3' & \\
\hline \multirow[t]{2}{*}{ CYP3A4 } & Forward & 5'-ATCATTGCTGTCTCCAACCTTCAC-3' & 60 \\
\hline & Reverse & 5'-TGCTTCCCGCCTCAGATTTCTC-3' & \\
\hline \multirow[t]{2}{*}{$\beta$-actin } & Forward & 5'-TCCTTCTGCATCCTGTCAGCA-3' & 58 \\
\hline & Reverse & 5'-CAGGAGATGGCCACTGCCGCA-3' & \\
\hline
\end{tabular}

AMAXA systems were plated $\left(5 \times 10^{3}\right.$ cells $\left./ \mathrm{cm}^{2}\right)$ in each differentiation induction medium using a StemPro Adipogenesis and Osteogenesis differentiation kit (Gibco). Each medium was changed every other day. After approximately 21 days, cells were fixed with $4 \%$ paraformaldehyde and incubated for $1 \mathrm{~h}$ with Oil Red O (Sigma-Aldrich) for staining lipids and von Kossa with 5\% silver nitrate (Sigma-Aldrich) to visualize the calcium deposits.

To induce hepatogenic differentiation, PD-MSCs ${ }^{\text {PRL-1 }}$ (5 passages) were seeded $\left(5 \times 10^{3}\right.$ cells $\left./ \mathrm{cm}^{2}\right)$ in lowglucose Dulbecco's modified Eagle medium (DMEM; HyClone) supplemented with 40\% MCDB 201 medium (Sigma-Aldrich), 2\% FBS, and 1\% P/S coated with $5 \mu \mathrm{g} /$ $\mathrm{ml}$ type IV collagen. After $48 \mathrm{~h}$, the growth medium was replaced with low-glucose DMEM supplemented with $20 \mathrm{ng} / \mathrm{ml}$ epidermal growth factor (EGF; Peprotech), 10 $\mathrm{ng} / \mathrm{ml}$ basic fibroblast growth factor (bFGF; Peprotech), $10 \mathrm{ng} / \mathrm{ml}$ bone morphogenetic protein-4 (Peprotech), 40\% MCDB 201 medium, and 1\% P/S. Then, PDMSCs $^{\text {PRL-1 }}$ were cultured for an additional $48 \mathrm{~h}$. The cells were treated for another week in step-1 medium consisting of low-glucose DMEM supplemented with 20 $\mathrm{ng} / \mathrm{ml}$ hepatocyte growth factor (Peprotech), $10 \mathrm{ng} / \mathrm{ml}$ bFGF, 40\% MCDB 201 medium, 2\% FBS, and 1\% P/S to progress to the maturation step. Then, differentiation was induced by incubating PD-MSCs ${ }^{\text {PRL-1 }}$ for another week with step-2 medium consisting of low-glucose DMEM supplemented with $20 \mathrm{ng} / \mathrm{ml}$ oncostatin M (Peprotech), $1 \mu \mathrm{M}$ dexamethasone (Sigma-Aldrich), $1 \times$ ITS+ Premix (Sigma-Aldrich), 40\% MCDB 201 medium, $2 \% \mathrm{FBS}$, and $1 \% \mathrm{P} / \mathrm{S}$. During steps 1 and 2, the culture media were changed every other day. After 18 days, each plate of PD-MSCs ${ }^{\text {PRL-1 }}$ was incubated for $1 \mathrm{~h}$ at $37^{\circ} \mathrm{C}$ with $1 \mathrm{mg} / \mathrm{ml}$ indocyanine green (ICG) (Dong in Dang Pharm., Siheung, Korea) uptake as described previously [25].

\section{FACS analysis}

PD-MSCs ${ }^{\text {PRL-1 }}$ (5 passages) were stained with monoclonal antibodies specific for the following proteins to phenotype cell-surface antigens: CD34 (PE), CD90 (PE), HLA-ABC (FITC), HLA-DR (FITC) (BD Bioscience, San Diego, CA, USA), CD13 (PE) (BioLegend, San Diego, CA, USA), CD105 (PE) (R\&D Systems, Minneapolis, MN, USA), and HLA-G (FITC) (Abcam). After staining, cells were washed in PBS and treated with appropriate isotype antibodies (BD Biosciences, San Jose, CA, USA). Cells were analyzed by a FACSCalibur flow cytometer (Becton Dickinson, Franklin Lakes, NJ, USA). For each sample, at least 10,000 events were acquired.

\section{Teratoma formation}

To confirm teratoma formation by PD-MSCs ${ }^{\text {PRL-1 }}$, 9week-old male nonobese diabetic/severe combined immunodeficiency (NOD/SCID) mice (Laboratory Animal Research Center, Bungdang CHA Medical Center, Seongnam, Korea) were housed in an air-conditioned animal facility under pathogen-free conditions. A total of $5 \times 10^{5}$ cells of each cell type (lenti and AMAXA) were transplanted into one testis $(\mathrm{Tx} ; n=2)$. The other testis was not injected (Con; $n=2$ ). After the testes were maintained for 14 weeks, the mice were sacrificed, and the testes of all groups were collected. Each section of testis tissue was stained with $H \& E$.

\section{Migration assay}

Naïve and PD-MSCs ${ }^{\text {PRL-1 }}\left(2 \times 10^{4}\right.$ cells $)$ were seeded into the upper inserts of a Transwell chamber $(8-\mu \mathrm{m}$ pore size; Corning) with or without siRNA-PRL-1 after $24 \mathrm{~h}$ to analyze the migration ability of naïve and PDMSCs $^{\text {PRL-1 }}$. A scrambled siRNA (Invitrogen) was used as a negative control (NC). Each cell type was fixed with $100 \%$ methanol for $10 \mathrm{~min}$ and then stained with Mayer's hematoxylin (Dako, Santa Clara, CA, USA) for $5 \mathrm{~min}$. The number of stained cells was randomly counted in eight nonoverlapping fields on the membranes at a magnification of $\times 200$. The experiments were performed in triplicate. 
Table 2 Human primer sequences using quantitative real-time polymerase chain reaction

\begin{tabular}{|c|c|c|c|}
\hline Genes & & Primer sequences & $\mathrm{Tm}$ \\
\hline \multirow[t]{2}{*}{ OC } & Forward & 5'-CACTCCTCGCCCTATTGGC-3' & 58 \\
\hline & Reverse & 5'-CCCTCCTGCTTGGACACAAAG-3' & \\
\hline \multirow[t]{2}{*}{ COL1A1 } & Forward & 5'-AGACATCCCACCAATCACCT-3' & 60 \\
\hline & Reverse & 5'-CGTCATCGCACAACACCT-3' & \\
\hline \multirow[t]{2}{*}{ Adipsin } & Forward & 5'-GGTCACCCAAGCAACAAAGT-3' & 60 \\
\hline & Reverse & 5'-CCTCCTGCGTTCAAGTCATC-3' & \\
\hline \multirow[t]{2}{*}{ PPAR- $\gamma$} & Forward & 5'-TTGACCCAGAAAGCGATTCC-3' & 60 \\
\hline & Reverse & 5'-AAAGTTGGTGGGCCAGAATG-3' & \\
\hline \multirow[t]{2}{*}{ PRL-1 } & Forward & 5'-TACTGCTCCACCAAGAAGCC-3' & 60 \\
\hline & Reverse & 5'-AGGTTTACCCCATCCAGGTC-3' & \\
\hline \multirow[t]{2}{*}{ RhoA } & Forward & 5'-TGGAAAGCAGGTAGAGTTGG-3' & 60 \\
\hline & Reverse & 5'-GACTTCTGGGGTCCACTTTT-3' & \\
\hline \multirow[t]{2}{*}{ ROCK1 } & Forward & 5'-GAAGAAAGAGAAGCTCGAGA-3' & 60 \\
\hline & Reverse & 5'-GATCTTGTAGCTCCCGCATCTGT-3' & \\
\hline \multirow[t]{2}{*}{ Alu } & Forward & 5'-GGAGGCTGAGGCAGGAGAA-3' & 55 \\
\hline & Reverse & 5'-CGGAGTCTCGCTCTGTCGCCCA-3' & \\
\hline \multirow[t]{2}{*}{$P G C-1 a$} & Forward & 5'-CAGCAAAAGCCACAAAGACG-3' & 60 \\
\hline & Reverse & 5'-GGGTCAGAGGAAGAGATAAAGTTG-3' & \\
\hline \multirow[t]{2}{*}{ NRF1 } & Forward & 5'-GCTTCAGAATTGCCAACCAC-3' & 60 \\
\hline & Reverse & 5'-GTCATCTCACCTCCCTGTAAC-3' & \\
\hline \multirow[t]{2}{*}{ mtTFA } & Forward & 5'-GAACAACTACCCATATTTAAAGCTCA-3' & 60 \\
\hline & Reverse & 5'-GAATCAGGAAGTTCCCTCCA-3' & \\
\hline \multirow[t]{2}{*}{ mtDNA } & Forward & 5'-CCACTGTAAAGCTAACTTAGCATTAACC-3' & 55 \\
\hline & Reverse & 5'-GTGATGAGGAATAGTGTAAGGAGTATGG-3' & \\
\hline \multirow[t]{2}{*}{ nuclearDNA } & Forward & 5'-CCAGAAAATAAATCAGATGGTATGTAACA-3' & 55 \\
\hline & Reverse & 5'-TGGTTTAGGAGGGTTGCTTCC-3' & \\
\hline \multirow[t]{2}{*}{ GAPDH } & Forward & 5'-GCACCGTCAAGGCTGAGAAC-3' & 60 \\
\hline & Reverse & 5'-GTGGTGAAGACGCCAGTGGA-3' & \\
\hline
\end{tabular}

Table 3 Rat primer sequences using quantitative real-time polymerase chain reaction

\begin{tabular}{|c|c|c|c|}
\hline Genes & & Primer sequences & $\mathrm{Tm}$ \\
\hline \multirow[t]{2}{*}{ PGC-1a } & Forward & 5'-GTGCAGCCAAGACTCTGTATGG-3' & 60 \\
\hline & Reverse & 5'-GTCCAGGTCATTCACATCAAGTTC-3' & \\
\hline \multirow[t]{2}{*}{ NRF1 } & Forward & 5'-GCTGTCCCACTCGTGTCGTAT-3' & 60 \\
\hline & Reverse & 5'-GTTGAGTCTAACCCATCTATCCG-3' & \\
\hline \multirow[t]{2}{*}{ mtTFA } & Forward & 5'-CGCCTAAAGAAGAAAGCACA-3' & 60 \\
\hline & Reverse & 5'-GCCCAACTTCAGCCATTT-3' & \\
\hline \multirow[t]{2}{*}{ mtD-Loop } & Forward & 5'-GGTTCTTACTTCAGGGCCATCA-3' & 55 \\
\hline & Reverse & 5'-GATTAGACCCGTTACCATCGAGAT-3' & \\
\hline \multirow[t]{2}{*}{$\beta$-actin } & Forward & 5'-GGGATGTTTGCTCCAACCAA-3' & 55 \\
\hline & Reverse & 5'-GCGCTTTTGACTCAAGGATTTAA-3' & \\
\hline \multirow[t]{2}{*}{ GAPDH } & Forward & 5'-TCCCTCAAGATTGTCAGCAA-3' & 60 \\
\hline & Reverse & 5'-AGATCCACAACGGATACATT-3' & \\
\hline
\end{tabular}

\section{L-lactate production assay}

To confirm the end product of glycolysis in naïve and PD-MSCs ${ }^{\text {PRL-1 }}$, the lactate production rate was determined using a colorimetric L-lactate assay kit (Abcam). Cell lysates were deproteinized to eliminate endogenous LDH by a Deproteinizing Sample Preparation Kit-TCA (Abcam). Each sample was plated in a 96-well plate, and lactate reagent was added for $30 \mathrm{~min}$. The absorbance was quantified using an Epoch microplate reader (BioTek, Winooski, VT, USA) at $450 \mathrm{~nm}$. The lactate concentration was evaluated by the trend line equation. The experiments were conducted in triplicate.

\section{Measurement of ATP production}

To confirm that mitochondria provide energy, ATP concentrations of homogenized liver tissue samples, PD$\mathrm{MSCs}^{\mathrm{PRL}-1}$, and primary hepatocyte lysate were measured by an ATP determination kit (Thermo Fisher 
Scientific, Waltham, MA, USA). According to the manufacturer's instructions, ATP concentrations were assessed using a microplate reader (BioTek) at $570 \mathrm{~nm}$. The experiments were performed in triplicate.

\section{Mitochondrial DNA (mtDNA) copy number assay}

Genomic DNA (gDNA) was extracted from MSCs, primary hepatocytes, and homogenized BDL-injured rat liver to analyze mtDNA copy number. qRT-PCR amplification was conducted with specific primers (Table 2) containing $250 \mathrm{ng}$ of gDNA, primers of nuclear DNA with FAM- and mtDNA with JOE-labeled quencher dye, and 1× TaqMan Universal Master Mix (Applied Biosystems, Foster City, CA, USA) according to the manufacturer's instructions. Data were obtained in triplicate.

\section{XF Mito Stress assay}

To further analyze mitochondrial metabolic functions in live PD-MSCs ${ }^{\text {PRL-1 }}$, an XF24 Extracellular Flux Analyzer (Seahorse Bioscience, North Billerica, MA, USA) was used for real-time analysis of the oxygen consumption rate (OCR) and extracellular acidification rate (ECAR). Naïve and PD-MSCs ${ }^{\text {PRL-1 }}$ were plated on XF24-well microplates (Seahorse Bioscience) $\left(7 \times 10^{3}\right.$ cells/well). The cells were adjusted for equilibrium in XF buffer for 60 min for contemporaneous analysis of OCR and ECAR by repeated cycles of mixing ( $3 \mathrm{~min}$ ), incubation $(2 \mathrm{~min})$, and measurement $\left(3 \mathrm{~min}\right.$ ) periods in a non- $\mathrm{CO}_{2}$ incubator. Following basal respiration measurements, the cells were sequentially treated with $0.5 \mu \mathrm{M}$ oligomycin, $0.5 \mu \mathrm{M}$ carbonyl cyanide-p-trifluoromethoxyphenylhydrazone (FCCP), and $1 \mu \mathrm{M}$ rotenone/antimycin A (AA) mixture. The changes in respiration were recorded. The Seahorse XF24 Analyzer program was set according to the manufacturer's recommendation. OCR/ECAR was then normalized by total cell number.

\section{Statistical analysis}

All data are expressed as the mean \pm standard deviation (SD). Student's $t$ test was used for analysis, and $p$ values less than 0.05 were considered statistically significant. All experiments were conducted in triplicate.

\section{Results}

Generation of stable PD-MSCs with PRL-1 using lentiviral and nonviral AMAXA systems

Naïve PD-MSCs at passage 8 were transfected with lentiviral and nonviral AMAXA plasmid tagged with GFP to overexpress PRL-1 in PD-MSCs (PD-MSCs ${ }^{\text {PRL-1 }}$, PRL-1+ ). A positive control was used for the GFP vector. After transfection, PD-MSCs generated using lentiviral vector containing $2 \mu \mathrm{g} / \mathrm{ml}$ puromycin and AMAXA containing $1.5 \mathrm{mg} / \mathrm{ml}$ neomycin were stabilized in conditioned medium (Fig. 1a). In each of these systems, GFP-positive
PD-MSCs ${ }^{\text {PRL-1 }}$ had spindle-like and fibroblastoid morphologies similar to those of MSCs (Fig. 1b). Overexpression of PRL-1 was confirmed in PD-MSCs ${ }^{\text {PRL-1 }}$ compared to naïve cells (Fig. 1c). In addition, RT-PCR results in $\mathrm{PD}-\mathrm{MSCs}{ }^{\mathrm{PRL}-1}$ revealed the expression of stemness markers (Oct4, Nanog, and Sox2) and telomerase reverse transcriptase (TERT). In particular, human leukocyte antigen (HLA)-G, which has an immunomodulatory effect, was expressed in both cell types (Fig. 1d).

We previously confirmed the characterization of naïve PD-MSCs [27]. The immunophenotypes of both types of PD-MSCs ${ }^{\text {PRL-1 }}$ were analyzed by flow cytometry. MSC marker clusters of differentiation (CD13, CD90, and CD105) were positive, whereas the hematopoietic and endothelial cell marker CD34 was negative in both types of PD-MSCs ${ }^{\text {PRL-1 }}$. Moreover, HLA-DR was nearly absent. However, HLA-ABC and HLA-G were significantly positive in PD-MSCs ${ }^{\text {PRL-1 }}$ (Fig. 1e). The protein levels of both cell types were higher than those of naïve cells (Fig. 1f). Nine-week-old male NOD/SCID mice were directly injected with PD-MSCs ${ }^{\text {PRL-1 }}$ into the testes $(n=2$; lentiviral, $n=2$; AMAXA) to confirm teratoma formation in vivo. Mice were sacrificed at 14 weeks postinjection, and each testis was evaluated by H\&E staining (Fig. 1g) and the human-specific Alu sequence from gDNA isolation. Testes injected with cells treated with both systems had no teratomas, and Alu expression was higher in injected testes than in noninjected testes (Fig. 1h). These findings indicated that PRL-1overexpressing PD-MSCs were generated using lentiviral and nonviral AMAXA systems and maintained characteristics similar to those of naïve cells.

\section{Multidifferentiation potential of PD-MSCs ${ }^{\text {PRL-1 }}$}

PD-MSCs ${ }^{\text {PRL-1 }}$ that differentiated into mesodermal lineages (osteogenic and adipogenic) were identified using von Kossa and Oil Red O staining (Fig. 2b, d). qRT-PCR revealed that the expression of osteogenic-specific markers (osteocalcin; $\mathrm{OC}$ and collagen type 1 alpha 1; COL1A1) was increased in differentiated compared with undifferentiated PD-MSCs ${ }^{\text {PRL-1 }}$ (Fig. 2a). In addition, the expression of adipsin and peroxisome proliferatoractivated receptor gamma (PPAR- $\gamma$ ), which are specific markers for adipocytes, was higher in differentiated cells than in undifferentiated cells (Fig. 2c). Furthermore, both types of PD-MSCs ${ }^{\text {PRL-1 }}$ differentiated into endodermal lineage hepatocytes. The mRNA expression of hepatogenic markers, including albumin, tyrosine aminotransferase (TAT), hepatocyte nuclear factor 1 homeobox A (HNF1A), cytochrome P450 2B6 (CYP2B6), and CYP3A4 was higher than differentiated PD-MSCs ${ }^{\text {PRL-1 }}$ than undifferentiated cells using both gene delivery systems (Fig. 2e). ICG uptake was evaluated in lentiviral and nonviral AMAXA PD-MSCs ${ }^{\text {PRL-1 }}$ 


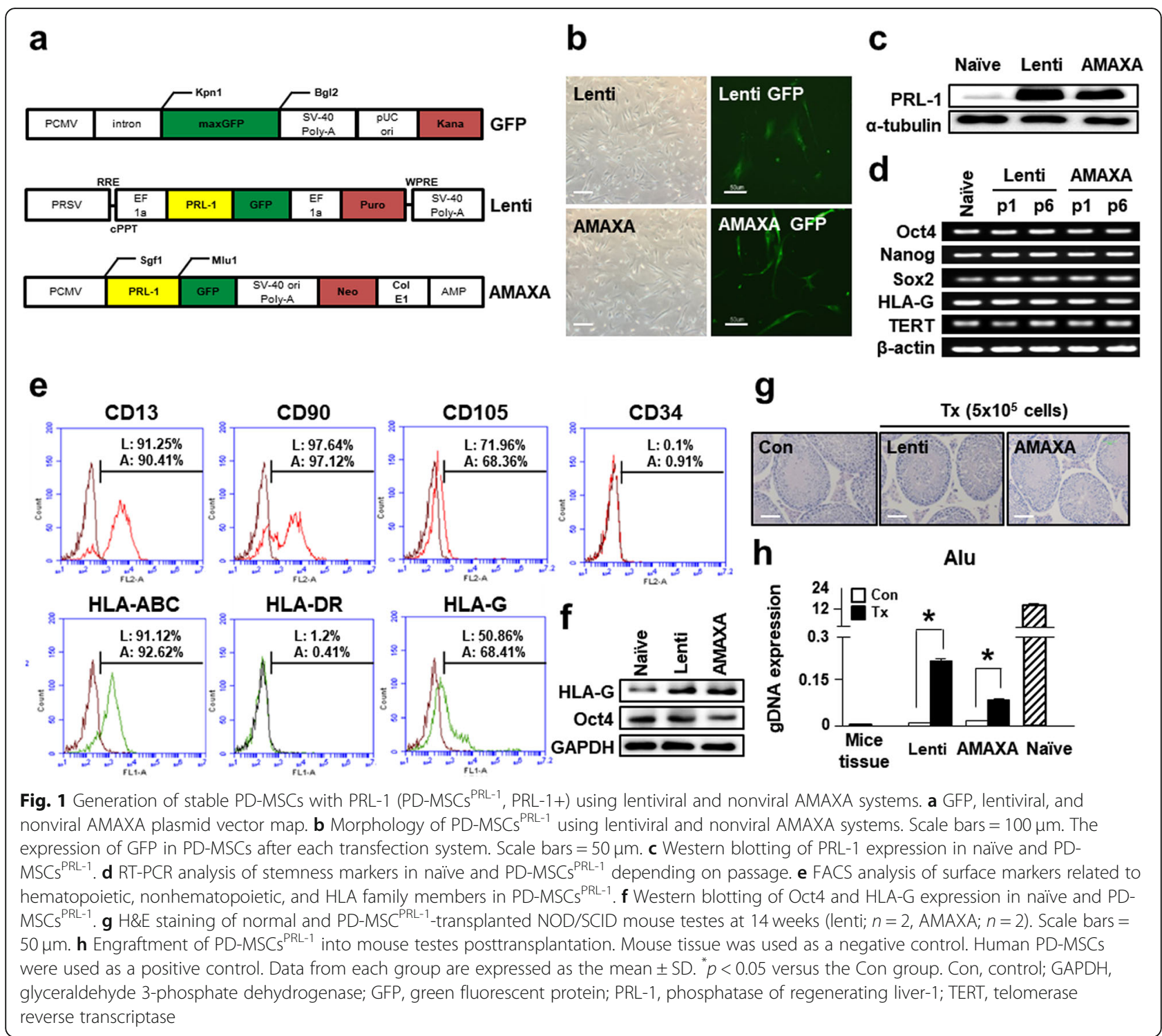

(Fig. 2f) to determine whether these cells exhibited hepatocyte function. These findings indicate that both types of PD-MSCs ${ }^{\text {PRL-1 }}$ retain the ability to differentiate into mesoderm and endodermal lineage cells.

\section{Effect of PRL-1-dependent migration ability through the Rho family}

To analyze the effect of PRL-1 on the migration ability of PD-MSCs ${ }^{\text {PRL-1 }}$, we performed a migration assay with PD-MSCs ${ }^{\text {PRL-1 }}$ using a Transwell insert system. The number of both types of migrated PD-MSCs ${ }^{\text {PRL-1 }}$ was higher than that of naive cells (Fig. 3a). In addition, the number of migrated naïve and PD-MSCs ${ }^{\text {PRL-1 }}$ was significantly decreased when cocultured with siRNA-PRL-1 treatment (Fig. 3b). PRL-1 expression as well as RhoA and ROCK1 expression was increased in PD-MSCs ${ }^{\text {PRL-1 }}$ compared with naïve cells. Alternatively, downregulated
PRL-1 decreased migration ability (Fig. 3c-e). Our data suggest that PRL-1 may regulate migration ability in a dependent manner.

Improved mitochondrial respirational metabolic states of PD-MSCs ${ }^{\text {PRL-1 }}$ regulate mitochondrial biogenesis

To analyze mitochondrial respiration in PD-MSCs ${ }^{\text {PRL-1 }}$ according to both gene delivery systems, we used the XF Cell Mito Stress test to evaluate the impact of mitochondrial complex inhibitors (oligomycin, FCCP, and rotenone/AA) on the electron transport chain (ETC). In particular, PD-MSCs ${ }^{\text {PRL-1 }}$ generated using the nonviral system had a more energetic metabolic state than did the cells in the naïve and lentiviral groups (Fig. 4a). The maximal respiration capacity, which may account for the capability of cells to respond to an energy demand, was increased in PD-MSCs ${ }^{\text {PRL-1 }}$ compared to naïve cells. In 

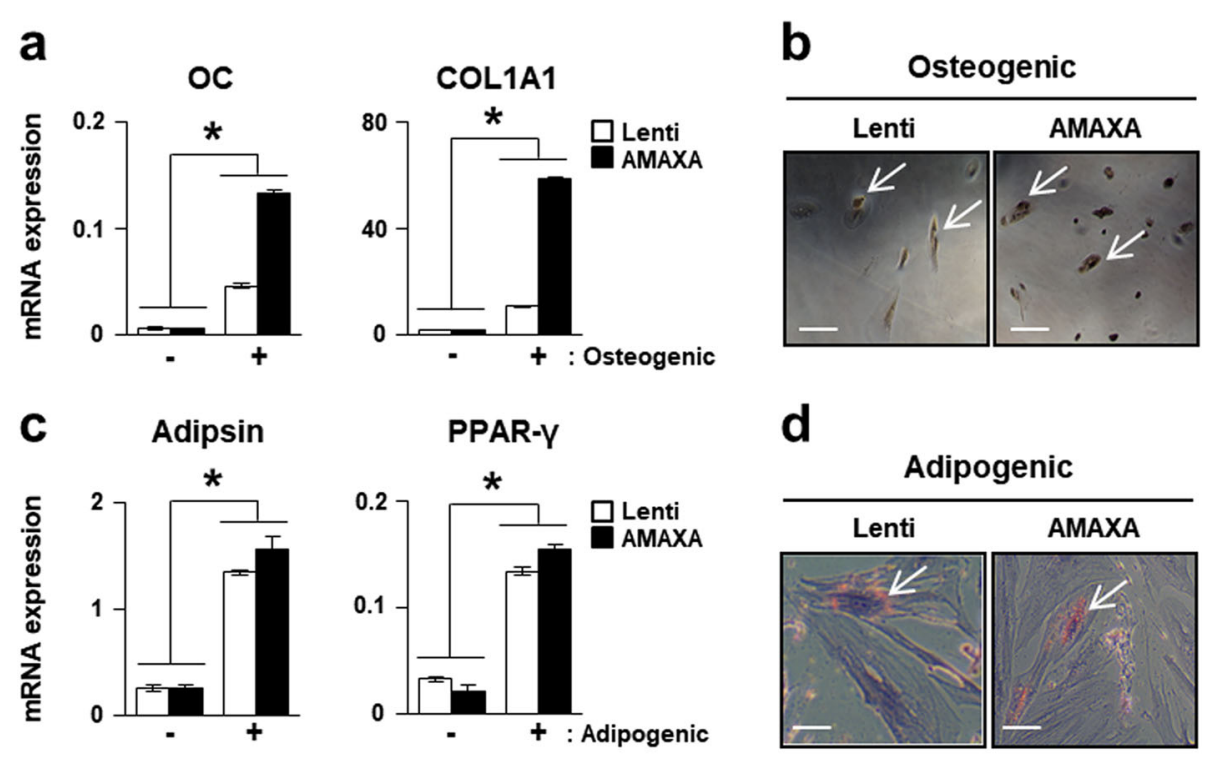

e

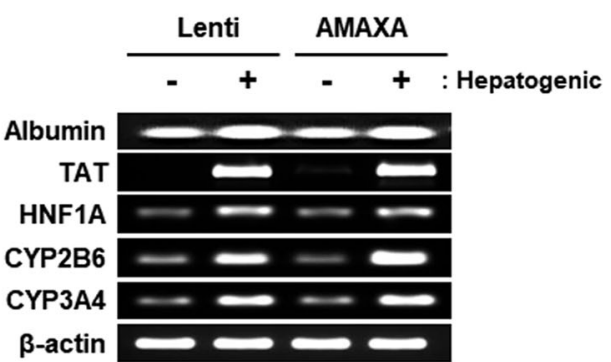

\section{$\mathbf{f}$}

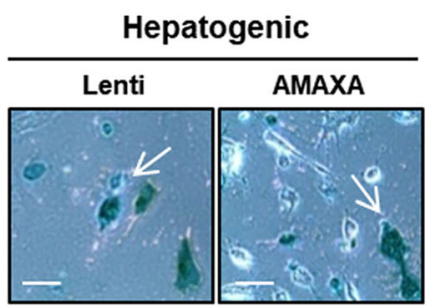

Fig. 2 Multidifferentiation potential of PD-MSCS ${ }^{\text {PRL-1 }}$. a qRT-PCR analysis of osteogenic markers (OC and COL1A1) in undifferentiated (-) and differentiated (+) PD-MSCS ${ }^{\text {PRL-1 }}$. b Von Kossa staining in osteogenic differentiation of PD-MSCs ${ }^{\text {PRL-1 }}$. Scale bars $=50 \mu m$. $\mathbf{c}$ qRT-PCR analysis of adipogenic markers (adipsin and PPAR- $\gamma$ ) in undifferentiated and differentiated PD-MSCS ${ }^{\text {PRL-1 }}$. $\mathbf{d}$ Oil Red $O$ staining in adipogenic differentiation of PD-MSCS ${ }^{P R L-1}$. Scale bars $=50 \mu \mathrm{m}$. e RT-PCR analysis of hepatocyte function markers (albumin, tyrosine aminotransferase; TAT, hepatocyte nuclear factor 1 homeobox A; HNF1A, cytochrome P450 2B6; CYP2B6, and CYP3A4) in undifferentiated and differentiated PD-MSCs ${ }^{\text {PRL-1 }}$. f ICG uptake in PD-MSCS ${ }^{\text {PRL-1 }}$ after hepatogenic differentiation. Scale bars $=50 \mu \mathrm{m}$. Data from each group are expressed as the mean \pm SD. ${ }^{*} p<0.05$ versus undifferentiated group. COL1A1, collagen type 1 alpha 1; CYP2B6, cytochrome P450 2B6; HNF1A, hepatocyte nuclear factor 1 homeobox A; OC, osteocalcin; PPAR- $\gamma$, peroxisome proliferator-activated receptor gamma; TAT, tyrosine aminotransferase

particular, nonviral system-based PD-MSCs ${ }^{\text {PRL-1 }}$ showed significant improvement in this capacity (Fig. 4b). In whole-cell lysates, ATP, the mitochondrial final product, was also relatively increased in PD-MSCs ${ }^{\text {PRL-1 }}$ generated using both systems compared with that in naïve cells (Fig. 4c).

Interestingly, although naïve and PD-MSCs ${ }^{\text {PRL-1 }}$ using lentiviral groups showed no differences, intracellular ATP production in live cells in the nonviral AMAXA system group markedly improved (Fig. 4d). mtDNA copy number was confirmed to isolate gDNA from naive and PD$\mathrm{MSCs}^{\mathrm{PRL}-1}$ and investigate self-renewal ability through mitochondrial function. mtDNA copy number was higher in PD-MSCs ${ }^{\text {PRL-1 }}$ than in naïve cells (Fig. 4e). In particular, PD-MSC ${ }^{\text {PRL-1 }}$ in the AMAXA system group prominently had a higher mtDNA copy number. The production of L-lactate, the end product of glycolysis, was assayed. L- lactate levels decreased in PD-MSCs ${ }^{\text {PRL-1 }}$ generated using both systems compared with those in naïve cells (Fig. 4f). In glycolysis, pyruvate that forms under aerobic conditions undergoes conversion to acetyl Co-A by pyruvate dehydrogenase $(\mathrm{PDH})$. Although heat shock protein 60 , which mediates protein folding after import into the mitochondria, and prohibitin 1 (PHB1), which exhibits membrane-bound ring complex expression, showed no differences, the protein expression of PDH was higher in enhanced PD-MSCs ${ }^{\text {PRL-1 }}$ generated using both systems than in naïve systems. In mitochondria, to produce ATP, succinate dehydrogenase (SDHA), a key component in Complex II of the ETC, increased in PD-MSCs ${ }^{\text {PRL-1 }}$ generated using lentiviral and nonviral systems. The expression of cytochrome c (cyt c) related to Complex 4 of the ETC and cyt $\mathrm{c}$ oxidase (COX10) also increased in PDMSCs $^{\text {PRL-1 }}$. In addition, through voltage-dependent anion 


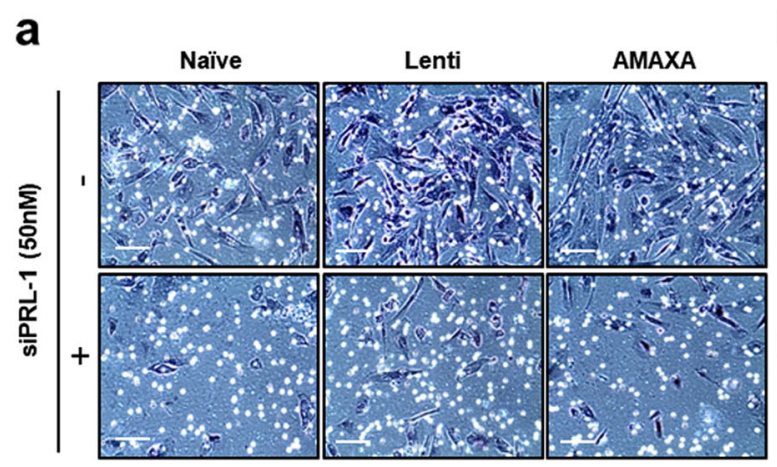

b
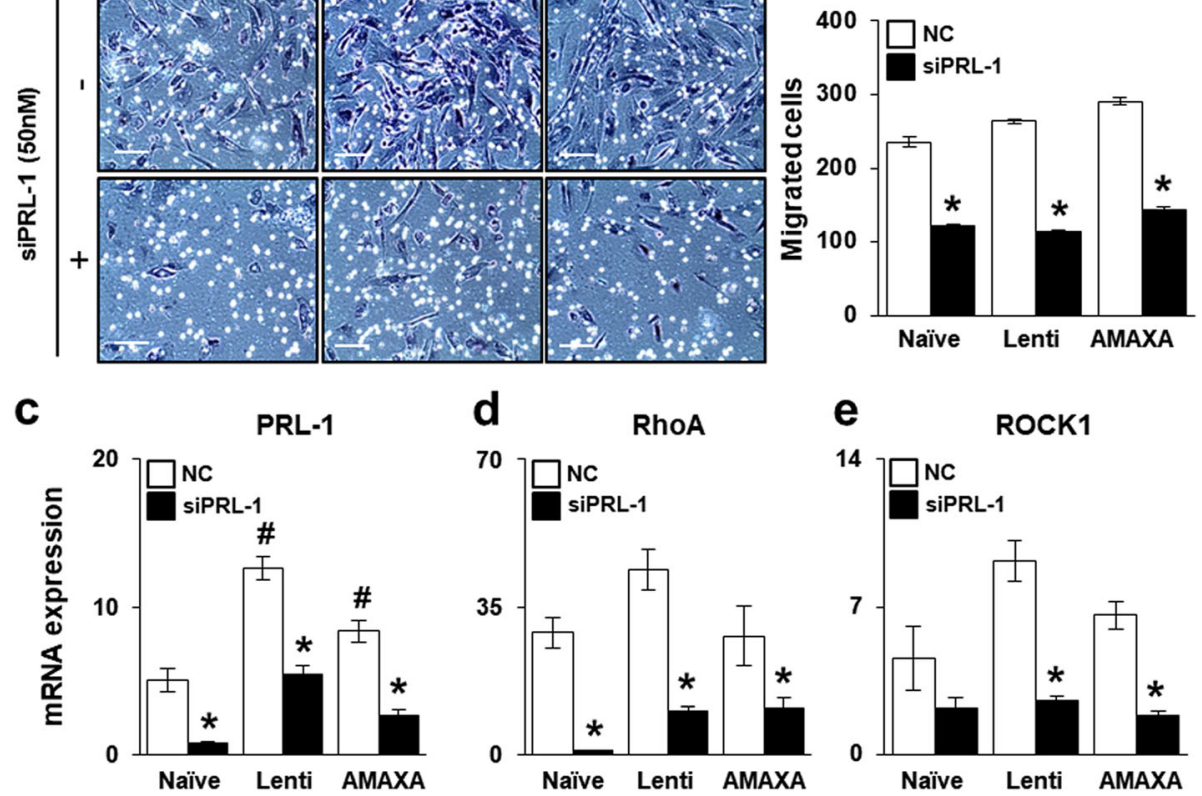

Fig. 3 Effect of PRL-1-dependent migration ability through the Rho family. $\mathbf{a}, \mathbf{b}$ Representative images and quantification of migrated naive and PD-MSCs ${ }^{\text {PRL-1 }}$ in a Transwell insert system treated or untreated with siRNA-PRL-1 (siPRL-1; $50 \mathrm{nM}$ ) after $24 \mathrm{~h}$. Scale bars $=100 \mu \mathrm{m}$. QRT-PCR analysis of $\mathbf{c}$ PRL-1, $\mathbf{d}$ RhOA, and e ROCK1 expression in migrated naïve and PD-MSCS ${ }^{\text {PRL-1 }}$ from the upper chamber to the lower chamber after treatment with or without siPRL-1. Data from each group are expressed as the mean \pm SD. ${ }^{*} p<0.05$ versus NC; ${ }^{\#} p<0.05$ versus naïve. $N C$, negative control; PRL-1, phosphatase of regenerating liver-1

channels (VDAC) located in the mitochondrial outer membrane, superoxide free radicals are rapidly converted to $\mathrm{H}_{2} \mathrm{O}_{2}$ by superoxide dismutase 1 (SOD1) in the aerobic system [28].

Although VDAC expression in PD-MSCs ${ }^{\text {PRL-1 }}$ was markedly higher than that in naïve cells, SOD1 showed no differences (Fig. 4g and Supplementary Fig. 1). In mammals, improvement in aerobic metabolic capacity occurs through transcriptionally regulated mitochondrial biogenesis [29]. The major factors in biogenesis (PGC$1 \alpha$, nuclear respiratory factor 1 ; NRF1 and mtTFA) were detected by mRNA levels. Although NRF1 expression showed no differences following downregulation of PRL1 , PGC- $1 \alpha$ and mtTFA expression significantly decreased after PRL-1 knockdown (Fig. 4h). These results suggest that enhanced PRL-1 in PD-MSCs using both gene delivery systems may affect mitochondrial biogenesis, particularly PRL-1 induced by the nonviral AMAXA system, promoting cellular aerobic metabolism.

\section{In vivo nonviral PD-MSCs ${ }^{\mathrm{PRL}-1}$ alleviate liver fibrosis in a rat model of $\mathrm{BDL}$}

BDL is the most common model of cholestasis injury in rodents and results in inflammation, hepatocyte apoptosis and fibrosis [30]. To analyze the hepatic regeneration of PD-MSCs ${ }^{\text {PRL-1 }}$ generated using a nonviral
AMAXA system in the BDL model, we established an early cirrhotic model. Ten days after BDL, we distributed the animals into the following groups: normal control group (Con), nontransplantation group (NTx), naïve PD-MSC transplantation group (TTx naïve), and PDMSC $^{\text {PRL-1 }}$ transplantation group (TTx PRL-1+) (Fig. 5a). To evaluate the intrahepatic distribution of transplanted cells, PKH67+ cells were identified among the vein and periportal fibrotic area in the liver sections of TTx naïve and PRL-1+ groups at 1 week (Fig. 5b). In comparison to the livers in the normal control rats, those in the BDLinduced NTx group exhibited diffuse bile ductular proliferation with loss of enlarged hepatocytes. Histopathological analysis determined that the collagen fibrotic area was distinctly increased. Compared with the NTx rats, the transplanted rats showed decreased Sirius red and Masson's trichrome-stained collagen fiber areas, and their hepatocytes were partly replaced by ductules at 3 weeks (Fig. 5c). In particular, compared with the TTx naive group rats, the transplanted TTx PRL-1+ rats exhibited significantly decreased quantification of the fibrotic area based on Sirius red and Masson's trichrome staining (Fig. 5d, e). These findings indicate that administration of $\mathrm{PD}-\mathrm{MSCs}{ }^{\mathrm{PRL}-1}$ induced by a nonviral AMAXA gene delivery system decreased liver fibrosis in a rat BDL model. 


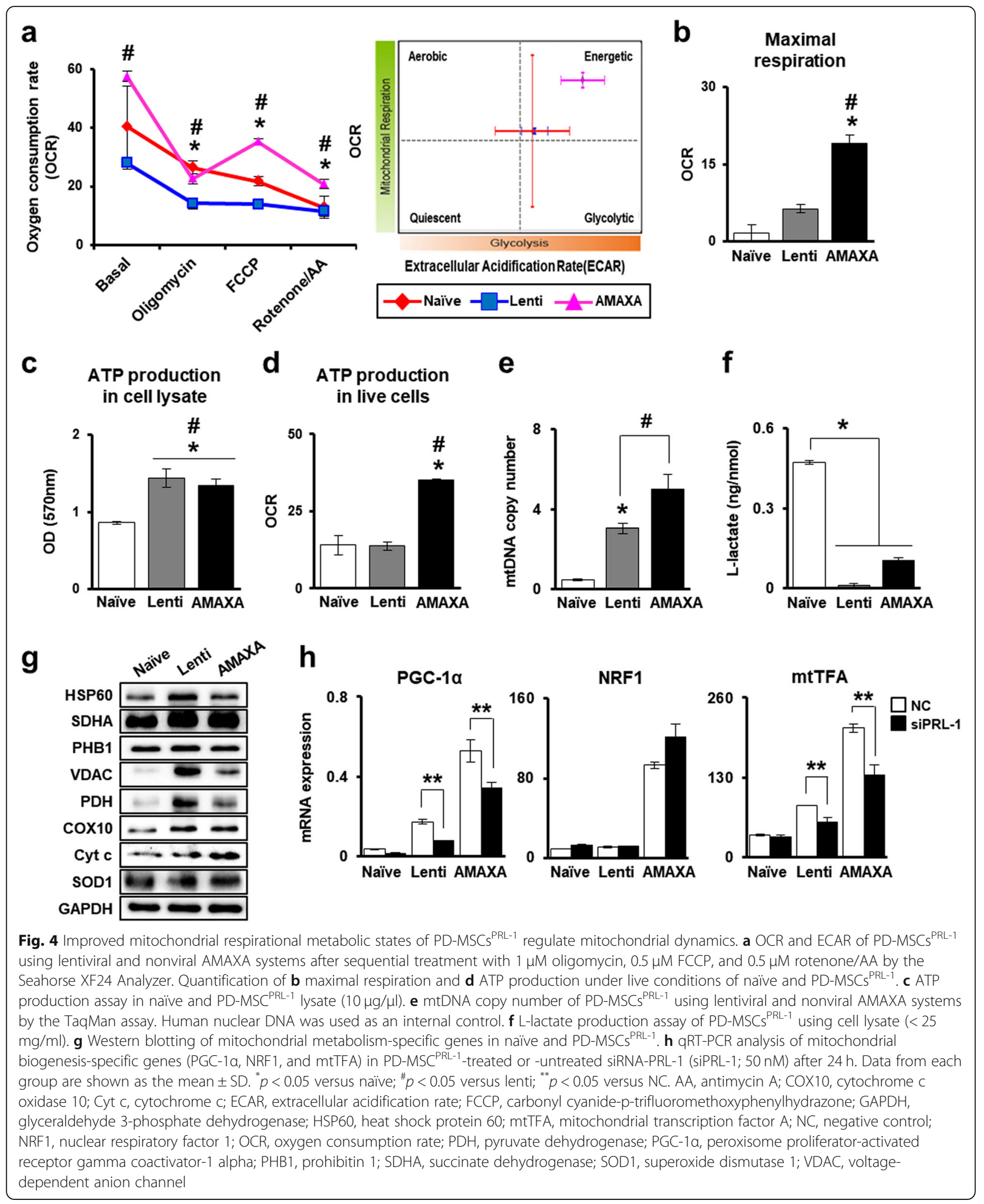




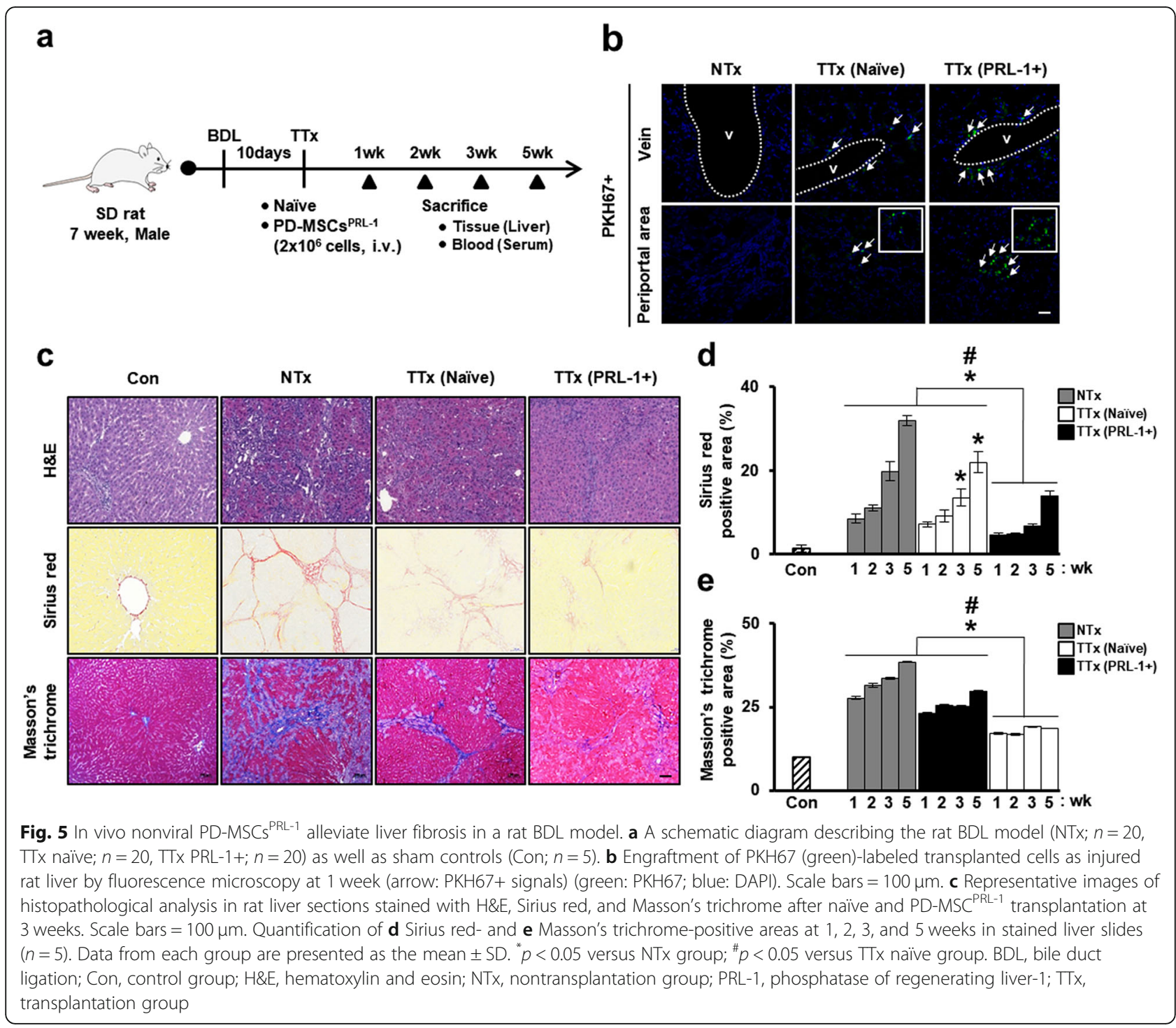

PD-MSCs ${ }^{\text {PRL-1 }}$ from a nonviral system enhance hepatic function by regulating mitochondrial metabolism in a rat BDL model

mRNA and protein expression of albumin were increased in the transplantation groups compared with the NTx group, and these findings confirmed hepatic function by PD-MSC ${ }^{\text {PRL-1 }}$ transplantation in BDLinjured rat livers. Albumin levels as well as human PRL-1 expression were remarkably higher in the TTx PRL-1+ group than in the TTx naïve group at 1 week (Fig. 6a, b). In addition, increased serum levels of ALT, AST, and TBIL and decreased albumin levels were confirmed in the NTx group compared to the Con group. Although TBIL levels in TTx PRL-1+ livers showed no differences compared with TTx naïve livers, the serum levels of ALT, AST, and albumin were markedly improved (Table 4). The protein expression of RhoA and ROCK1 was increased in the TTx groups compared with that in the NTx group. Interestingly, the TTx PRL-1 group showed significantly higher expression of CDK4 and Cyclin D1 than did the TTx naïve group (Fig. 6c). To demonstrate alterations in hepatic metabolism induced by PD-MSCs ${ }^{\text {PRL-1 }}$ in $\mathrm{BDL}$, the protein levels of mitochondrial metabolism-specific markers (PDH, SDHA, ATP5B, and PHB1) were significantly increased in the TTx PRL-1+ group compared with the NTx and TTx naïve groups (Fig. 6d). Moreover, mtDNA copy number and ATP production in the naïve transplantation group were higher than those in the NTx group. In particular, compared with the TTx naïve group, the TTx PRL-1+ group showed remarkably enhanced mtDNA copy number and ATP production (Fig. 6e, f). These findings indicate that PD-MSCs ${ }^{\text {PRL-1 }}$ induced by a nonviral AMAXA gene delivery system may promote hepatic function by regulating mitochondrial metabolism in the liver. 
a

$$
\begin{aligned}
& \text { NTx TTx (Naïve) TTx (PRL-1+) } \\
& \text { Con } \begin{array}{lllllllllllll}
1 & 2 & 3 & 5 & 1 & 2 & 3 & 5 & 1 & 2 & 3 & 5 & \text { : wk }
\end{array}
\end{aligned}
$$

Albumin $\mathrm{Q}-\ldots-\infty-\cdots$

PRL-1

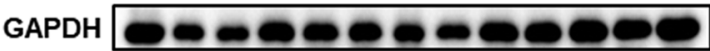

C

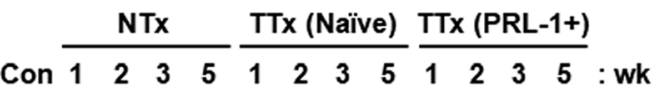

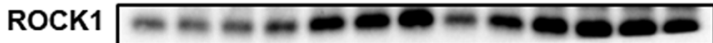

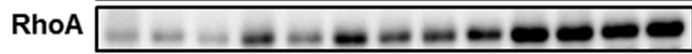

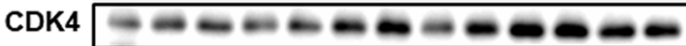

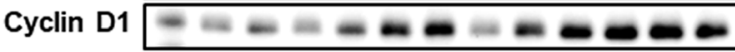

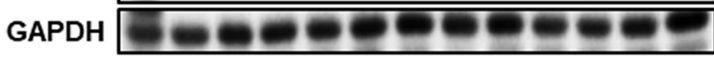

e

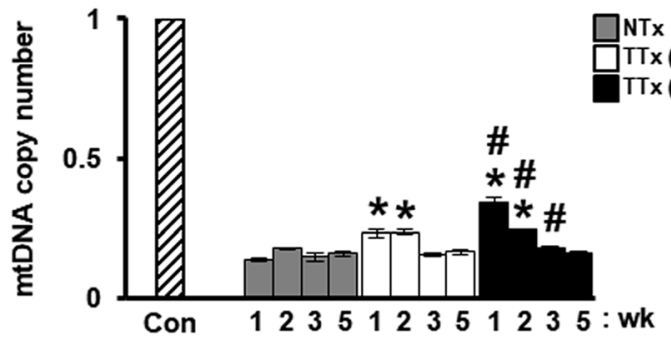

b

\section{Albumin}

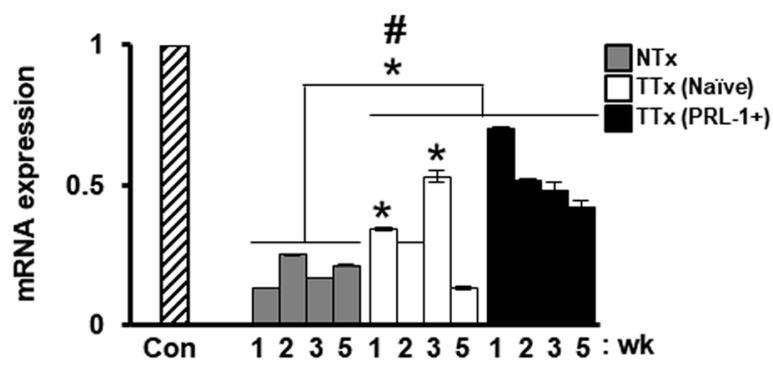

d

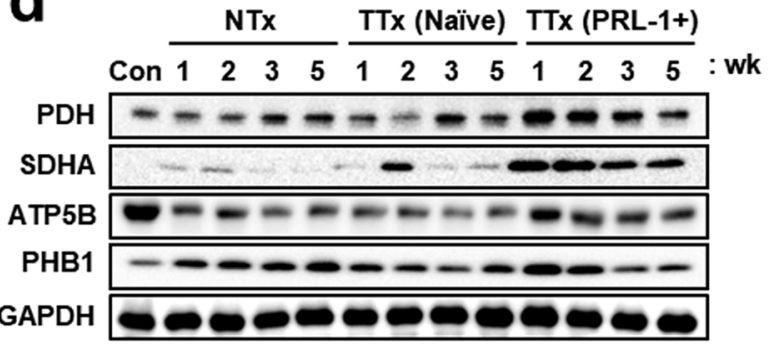

f

ATP production (nmol)

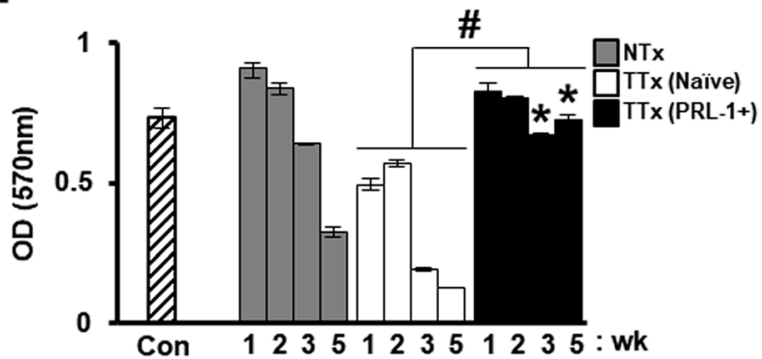

Fig. 6 PD-MSCS ${ }^{\text {PRL-1 }}$ using a nonviral system enhances hepatic function by regulating mitochondrial metabolism in a rat BDL model. a Western blotting of albumin and human PRL-1 gene expression by PD-MSC ${ }^{\text {RL-1 }}$ transplantation in pooled BDL-injured rat liver tissue $(n=5)$. $\mathbf{b}$ mRNA expression of albumin in a rat model with pooled BDL liver tissue $(n=5)$. Protein expression of the $\mathbf{c}$ Rho family (ROCK1 and RhoA), cell cycle (CDK4 and Cyclin D1), and mitochondrial metabolism (PDH, SDHA, ATP5B, and PHB1) by PD-MSC ${ }^{\text {PR-1 }}$ transplantation in pooled BDL-injured rat liver tissue $(n=5)$. e mtDNA copy number in BDL-injured rat liver tissue by the TaqMan assay. Rat nuclear DNA was used as an internal control. $\mathbf{f}$ ATP production assay in rat BDL liver lysate $(10 \mu \mathrm{g} / \mu \mathrm{ll})$. Data from each group are presented as the mean \pm SD. ${ }^{*} p<0.05$ versus NTx group; ${ }^{\#} p<$ 0.05 versus TTx naïve group. CDK4; cyclin-dependent kinase 4, Con, control group; GAPDH, glyceraldehyde 3-phosphate dehydrogenase; NTx, nontransplantation group; PDH, pyruvate dehydrogenase; PHB1, prohibitin 1; PRL-1, phosphatase of regenerating liver-1; SDHA, succinate

\begin{tabular}{|c|c|c|c|c|}
\hline & ALT (U/L) & AST (U/L) & TBIL $(\mu \mathrm{mol} / \mathrm{L})$ & Albumin (g/L) \\
\hline Normal control (Con) & $39.4 \pm 3.6$ & $97.1 \pm 7.3$ & $1.1 \pm 0.3$ & $34.4 \pm 2.3$ \\
\hline NTx & $152.8 \pm 7.2^{\dagger}$ & $797.4 \pm 32.0^{\dagger}$ & $121.1 \pm 4.8^{\dagger}$ & $21.5 \pm 0.5^{\dagger}$ \\
\hline TTx (naïve) & $125.6 \pm 6.9^{\dagger, *}$ & $690.9 \pm 34.7^{\dagger, *}$ & $96.5 \pm 5.3^{t^{, *}}$ & $24.2 \pm 0.5^{t, *}$ \\
\hline TTx (PRL-1+) & $104.0 \pm 9.1^{\dagger, *}, \#$ & $523.3 \pm 34.0^{+,{ }^{*}, \#}$ & $101.4 \pm 1.7^{\dagger, *}$ & $27.0 \pm 0.3^{+, *}, \#$ \\
\hline
\end{tabular}
dehydrogenase; $T \mathrm{x}$, transplantation group

Table 4 Improved liver functions according to MSC transplantation in rat serum levels of BDL model

Each group was $n=18$. Data are presented as mean \pm SD. ${ }^{\dagger} p<0.05$ versus Con group; ${ }^{*} p<0.05$ versus NTx group; ${ }^{*} p<0.05$ versus $T$ x naïve group. ALT; alanine aminotransferase, $A S T$; aspartate aminotransferase, Con; control group, TBIL; total bilirubin 


\section{PD-MSC ${ }^{\mathrm{PRL}-1}$ coculture activates the mitochondrial dynamics of primary hepatocytes}

To demonstrate hepatic mitochondrial function, primary hepatocytes were isolated from rats and cocultured with nonviral PD-MSCs ${ }^{\text {PRL-1 }}$ in accordance with PRL-1 knockdown. In vitro modeling was induced by LCA treatment for the accumulation of bile acid. In advance, the protein expression of albumin as well as that of PRL-1 in hepatocytes was decreased according to LCA treatment. However, compared to naïve cells, PDMSC $^{\text {PRL-1 }}$ coculture recovered the expression of albumin and PRL-1 (Fig. 7a). To verify the mitochondrial function of hepatocytes, although the protein expression of mitochondrial metabolism (PDH and ATP5B) decreased with LCA treatment, naïve PD-MSC coculture was slightly increased. Interestingly, PDH and ATP5B levels in $\mathrm{PD}-\mathrm{MSC}^{\mathrm{PRL}-1}$ coculture were higher than those in naïve cells (Fig. 7b). In addition, the mRNA levels of PGC- $1 \alpha$, NRF1, and mtTFA, which are key factors in mitochondrial dynamics, were decreased in the LCA treatment group. However, PD-MSC ${ }^{\mathrm{PRL}-1}$ coculture significantly improved gene expression (Fig. 7c). mRNA and protein expression was PRL-1-dependent. While mtDNA copy number and ATP production in primary hepatocytes receiving LCA treatment were reduced, compared to naïve cells, PD-MSC ${ }^{\mathrm{PRL}-1}$ coculture led to a significant increase (Fig. $7 \mathrm{~d}$, e). These data suggest that PD-MSCs ${ }^{\text {PRL-1 }}$ may stimulate improved mitochondrial metabolism in primary hepatocytes.

\section{Discussion}

As an alternative to liver transplantation, MSC-based therapy for regenerative medicine has been attempted for the treatment of various liver diseases, including hepatic failure and liver cirrhosis [31, 32]. According to our previous reports, PD-MSCs have antifibrotic effects by increased MMP activities as well as hepatic regeneration in a $\mathrm{CCl}_{4}$-injury rat model via an increased autophagic mechanism [27]. Recently, researchers have attempted clinical trials in patients with alcoholic hepatic cirrhosis using autologous BM-MSCs. In phase I and II clinical trials, Jang and colleagues reported that BM-MSCs were primarily safe and that autologous BM-MSCs had antifibrotic effects in patients with alcoholic hepatic cirrhosis [33]. Nevertheless, clinical applications of BM-MSCs have been hampered by several weaknesses, including a painful isolation procedure for patients, a lack of fresh cells, a high price, and a lack of understanding of the therapeutic mechanism [34]. The production of functionally enhanced MSCs with therapeutic efficacyenhancing factors and verification of therapeutic efficacy are emerging to overcome these limitations of MSCbased cell therapy.
Recently, PRL-1 has been shown to play an important role in cell cycle progression during hepatic regeneration [22]. However, the effect of PRL-1 on PD-MSC properties remains poorly understood. In our study, we demonstrated that PRL-1-overexpressing PD-MSCs (PDMSCs $^{\text {PRL-1 }}$, PRL-1+) were successfully generated using lentiviral and nonviral AMAXA gene delivery systems, and we analyzed their characteristics, which were similar to those of naïve cells (Figs. 1 and 2). Interestingly, the mitochondrial respirational metabolic state and cellular aerobic metabolism significantly increased in PD$\mathrm{MSCs}^{\mathrm{PRL}-1}$ in both gene delivery systems. In particular, mtDNA synthesis and mitochondrial biogenesis were remarkably enhanced by PRL-1 in the nonviral AMAXA system, and ATP production in mitochondria in live cellular conditions also increased, maintaining an energetic state (Fig. 4). Although differences in cellular mitochondrial mechanisms according to gene delivery systems have remained unclear, viral systems carry a possible risk of cancer and immunologic side effects [35].

In general, MSCs genetically engineered by viral gene delivery systems have important safety issues, such as the genomic instability of the cells. For this reason, many researchers have attempted to produce stem cells with enhanced function based on nonviral gene delivery systems, such as AMAXA systems, and have also applied them to clinical trials using enhanced functional stem cells. In the present study, PD-MSCs ${ }^{\text {PRL-1 }}$ were generated using nonviral AMAXA systems, and no teratoma formation occurred. Our studies revealed that compared with naïve PD-MSC transplantation, nonviral PDMSC $^{\text {PRL-1 }}$ transplantation remarkably enhanced engraftment in the injured target organs through the activated Rho family and albumin synthesis (Fig. 6). These data are similar to previous studies demonstrating that PRL-1 binding to p115 Rho GAP promotes ERK1/2 and RhoA activation [19].

Mitochondria-mediated function is associated with liver regeneration [36]. In chronic cholestasis, mitochondrial dysfunction, associated with decreased activities of respiratory chain complexes, mitochondrial membrane potential, and ATP production, was characterized [37]. The lack of stimulation of mitochondrial biogenesis in a rat BDL model leads to severe depletions and deletions of mtDNA copy number [38]. Additionally, hepatic injury caused by cholestasis affects oxidative stress in mitochondria in the liver. PGC- $1 \alpha$ and mtTFA are impaired in the BDL model [39]. By transplantation of MSCs, hepatic mitochondrial dysfunctions are reversed by mediating the nuclear factor erythroid-derived 2related factor 2 (Nrf2)/HO1 pathway [40]. The effects of MSCs are due to the more rapid recovery of the number of mitochondria and the function of hepatic mitochondria [41]. These previous reports support our conclusion 


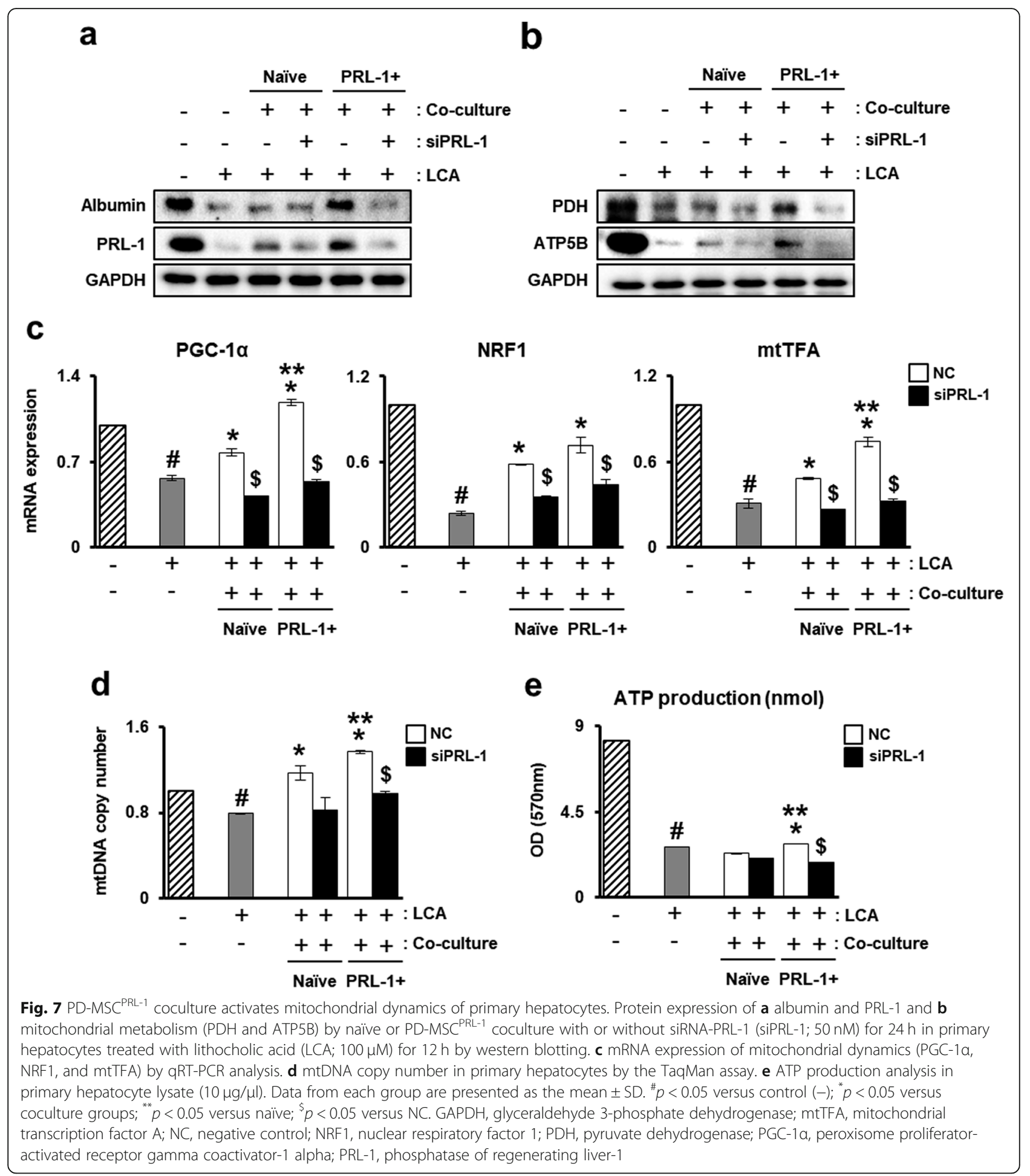

that mtDNA and ATP synthesis are increased in liver tissues during liver regeneration following transplantation of functionally enhanced PD-MSCs. PD-MSCs ${ }^{\text {PRL-1 }}$ generated using nonviral AMAXA system transplantation promoted mtDNA synthesis. Additionally, to promote hepatic ATP production, $\mathrm{PDH}$ and SDHA are more activated in hepatic mitochondrial ETCs in PD$\mathrm{MSCs}^{\mathrm{PRL}-1}$ than in naïve cells. Finally, hepatic ATP production was enhanced by PD-MSCs ${ }^{\text {PRL-1 }}$ generated using nonviral AMAXA system transplantation in a rat BDL model as well as primary hepatocytes (Figs. 7 and 8). Transplantation of PD-MSCs with PRL-1 using a 


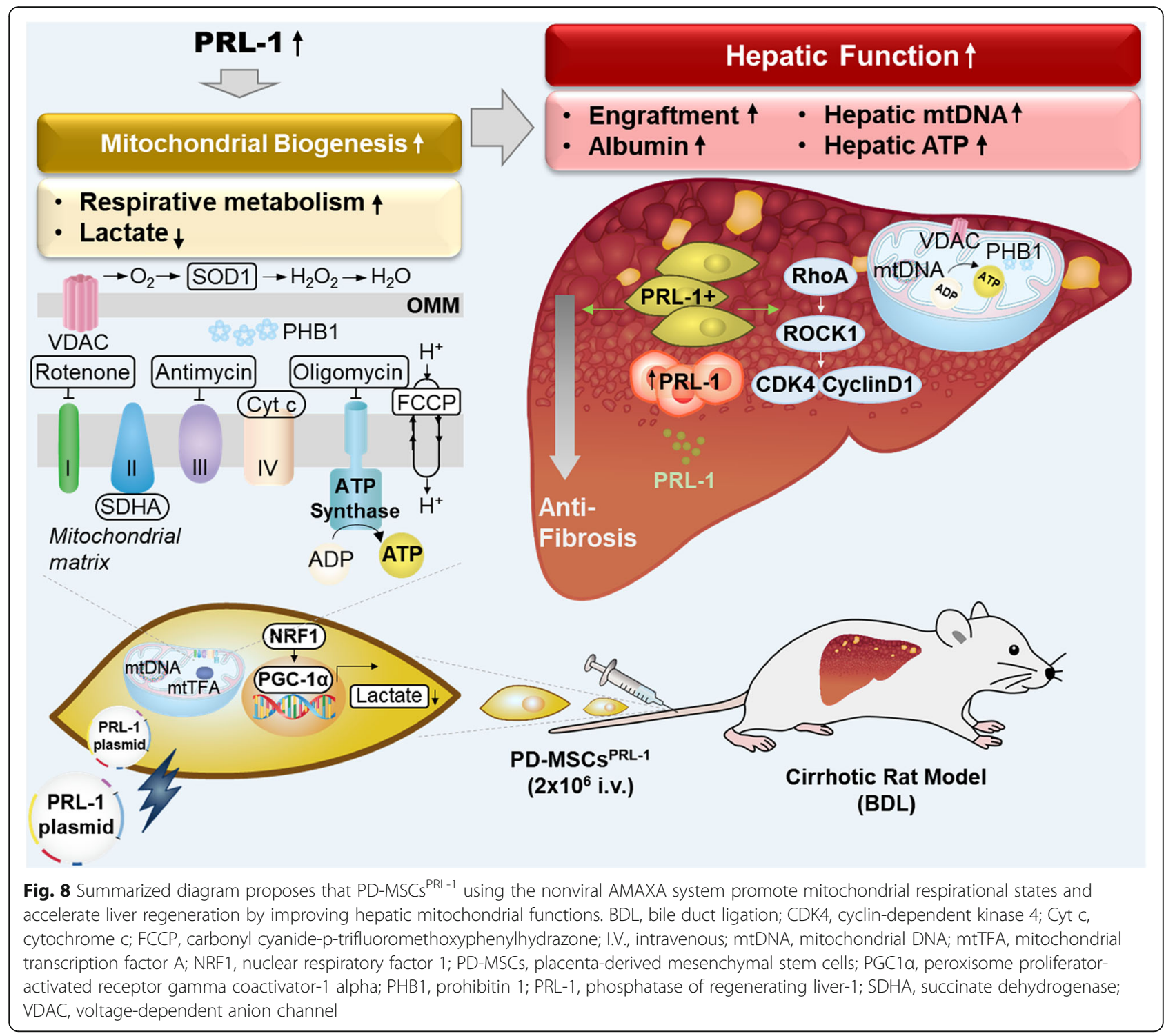

nonviral AMAXA system in a BDL rat hepatic disease model promotes hepatic functions by upregulating mitochondrial metabolism.

\section{Conclusion}

In conclusion, PD-MSCs ${ }^{\text {PRL-1 }}$ generated using the nonviral AMAXA system impacted mitochondrial respirational metabolic states more than those generated using the lentiviral-based gene delivery system. In particular, the therapeutic effects of PD-MSCs ${ }^{\text {PRL-1 }}$ using the nonviral AMAXA system accelerate liver function by promoting mitochondrial metabolism (Fig. 8). These findings provide novel insights into next-generation MSC-based cell therapy, including safe gene modification, and useful data for therapeutic strategies using PDMSCs for regenerative medicine in liver disease.

\section{Supplementary Information}

Supplementary information accompanies this paper at https://doi.org/10 1186/s13287-020-02029-3.

Additional file 1: Supplementary Fig. 1 Quantification of mitochondrial metabolism-specific genes in naïve and PD-MSCs ${ }^{\text {PRL-1 }}$ using both gene delivery systems. Data from each group are shown as the mean \pm SD. ${ }^{*} p<0.05$ versus naïve; $p<0.05$ versus lenti. COX10; cytochrome c oxidase 10, Cyt c; cytochrome C, GAPDH; glyceraldehyde 3phosphate dehydrogenase, HSP60; heat shock protein 60, PDH; pyruvate dehydrogenase, $P H B 1$; prohibitin 1, SDHA; succinate dehydrogenase, SOD1; superoxide dismutase 1,VDAC; voltage-dependent anion channel.

\section{Abbreviations}

AA: Antimycin A; ALT: Alanine aminotransferase; a-MEM: Alpha-modified minimal essential medium; AST: Aspartate aminotransferase; BDL: Bile duct ligation; bFGF: Basic fibroblast growth factor; BM-MSCs: Bone marrow-derived mesenchymal stem cell; $\mathrm{CCl}_{4}$ : Carbon tetrachloride; CD: Cluster of differentiation; COL1A1: Collagen type 1 alpha 1; COX10: Cytochrome C oxidase; Cyt c: Cytochrome c; CYP2B6: Cytochrome P450 2B6: DAPI: 4',6Diamidino-2-phenylindole; DMEM: Dulbecco's modified Eagle medium; 
ECAR: Extracellular acidification rate; EGF: Epidermal growth factor; ETC: Electron transport chain; FBS: Fetal bovine serum; FCCP: Carbonyl cyanide-p-trifluoromethoxyphenylhydrazone; GAPDH: Glyceraldehyde 3phosphate dehydrogenase; gDNA: Genomic DNA; GFP: Green fluorescent protein; hFGF-4: Human fibroblast growth factor-4; H\&E: Hematoxylin and eosin; HLA: Human leukocyte antigen; HNF1A: Hepatocyte nuclear factor 1 homeobox A; HO: Heme oxygenase; ICG: Indocyanine green; IL-6: Interleukin6; IRB: Institutional Review Board; MMP: Matrix metalloproteinase; mtDNA: Mitochondrial DNA; mtTFA: Mitochondrial transcription factor A; NBF: Neutral buffered formalin; NOD/SCID: Nonobese diabetic/severe combined immunodeficiency; NRF1: Nuclear respiratory factor 1; Nrf2: Nuclear factor erythroid-derived 2-related factor 2; OC: Osteocalcin; OCR: Oxygen consumption rate; PDH: Pyruvate dehydrogenase; PDMSCs: Placenta-derived mesenchymal stem cells; PGC-1a: Peroxisome proliferator-activated receptor gamma coactivator-1 alpha; PHB1: Prohibitin 1; PPAR-y: Peroxisome proliferator-activated receptor gamma; PRL1: Phosphatase of regenerating liver-1; P/S: Penicillin/streptomycin; PTP4A1: Protein tyrosine phosphatase type 4 A member 1; SD: SpragueDawley: SDHA: Succinate dehydrogenase; SOD1: Superoxide dismutase 1 STAT3: Signal transducer and activator of transcription 3; TAT: Tyrosine aminotransferase; TBIL: Total bilirubin; TERT: Telomerase reverse transcriptase; VDAC: Voltage-dependent anion channe

\section{Authors' contributions}

JYK did analysis and interpretation of data, and manuscript drafting. JHC and $\mathrm{JHJ}$ did analysis and collection of data. SP and JJ did interpretation of data and manuscript drafting. SHB helped critical discussion. GJK conceived and designed the experiments, and directed manuscript drafting, financial support and final approval of manuscript. All authors read and approved the final manuscript.

\section{Funding}

This research was supported by a grant of the Korea Health Technology R\&D Project through the Korea Health Industry Development Institute (KHIDI): funded by the Ministry of Health and Welfare, Republic of Korea (HI17C1050) and Basic Science Research Program through the National Research Foundation of Korea (NRF) funded by the Ministry of Education, Science and Technology (2020M3A9B302618221).

\section{Availability of data and materials}

All data analyzed for this study are included in this article.

\section{Ethics approval and consent to participate}

The animal experiments were approved by the IACUC of CHA University, Seongnam, Korea (IACUC-180023). The collection of placenta samples and their use for research purposes were approved by the IRB of CHA General Hospital, Seoul, Korea (IRB 07-18).

\section{Consent for publication}

Not applicable.

\section{Competing interests}

The authors declare that they have no competing interests.

\section{Author details}

'Department of Biomedical Science, CHA University, Seongnam 13488, Republic of Korea. ${ }^{2}$ Department of Oral Pathology, College of Dentistry, Gangneung-Wonju National University, Gangneung 25457, Republic of Korea. ${ }^{3}$ Department of Internal Medicine, Catholic University Medical College, Seoul 06591, Republic of Korea.

Received: 10 April 2020 Accepted: 16 November 2020

Published online: 27 November 2020

\section{References}

1. Volarevic V, Nurkovic J, Arsenijevic N, Stojkovic M. Concise review: therapeutic potential of mesenchymal stem cells for the treatment of acute liver failure and cirrhosis. Stem Cells. 2014;32(11):2818-23.

2. Weng J, Li W, Jia X, An W. Alleviation of ischemia-reperfusion injury in live steatosis by augmenter of liver regeneration is attributed to antioxidation and preservation of mitochondria. Transplantation. 2017;101(10):2340-8.
3. Sastre J, Serviddio G, Pereda J, Minana JB, Arduini A, Vendemiale G, Poli G, Pallardo FV, Vina J. Mitochondrial function in liver disease. Front Biosci. 2007 12:1200-9.

4. Perez-Carreras M, Del Hoyo P, Martin MA, Rubio JC, Martin A, Castellano G, Colina F, Arenas J, Solis-Herruzo JA. Defective hepatic mitochondrial respiratory chain in patients with nonalcoholic steatohepatitis. Hepatology. 2003;38(4):999-1007.

5. Valdecantos MP, Pardo V, Ruiz L, Castro-Sanchez L, Lanzon B, Fernandez-

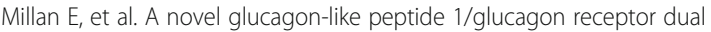
agonist improves steatohepatitis and liver regeneration in mice. Hepatology. 2017;65(3):950-68.

6. Han LH, Dong LY, Yu H, Sun GY, Wu Y, Gao J, Thasler W, An W. Deceleration of liver regeneration by knockdown of augmenter of liver regeneration gene is associated with impairment of mitochondrial DNA synthesis in mice. Am J Physiol Gastrointest Liver Physiol. 2015;309(2):G112-22.

7. Cai Y, Zou Z, Liu L, Chen S, Chen Y, Lin Z, Shi K, Xu L, Chen Y. Bone marrow-derived mesenchymal stem cells inhibits hepatocyte apoptosis after acute liver injury. Int J Clin Exp Pathol. 2015;8(1):107-16.

8. Kallis YN, Alison MR, Forbes SJ. Bone marrow stem cells and liver disease. Gut. 2007;56(5):716-24.

9. Zhang Z, Wang FS. Stem cell therapies for liver failure and cirrhosis. J Hepatol. 2013;59(1):183-5.

10. Pankaj $\mathrm{P}$, Zhang $\mathrm{Q}$, Bai $\mathrm{XL}$, Liang TB. Autologous bone marrow transplantation in decompensated liver: systematic review and metaanalysis. World J Gastroenterol. 2015;21(28):8697-710.

11. Ma XR, Tang YL, Xuan M, Chang Z, Wang XY, Liang XH. Transplantation of autologous mesenchymal stem cells for end-stage liver cirrhosis: a meta-analysis based on seven controlled trials. Gastroenterol Res Pract. 2015;2015:908275.

12. Pan $X N$, Zheng LQ, Lai XH. Bone marrow-derived mesenchymal stem cell therapy for decompensated liver cirrhosis: a meta-analysis. World J Gastroenterol. 2014;20(38):14051-7.

13. Mohamadnejad M, Namiri M, Bagheri M, Hashemi SM, Ghanaati H, Zare Mehrjardi N, Kazemi Ashtiani S, Malekzadeh R, Baharvand H. Phase 1 human trial of autologous bone marrow-hematopoietic stem cell transplantation in patients with decompensated cirrhosis. World J Gastroenterol. 2007;13(24): 3359-63.

14. Fukuchi Y, Nakajima H, Sugiyama D, Hirose I, Kitamura T, Tsuji K. Human placenta-derived cells have mesenchymal stem/progenitor cell potential. Stem Cells. 2004;22(5):649-58.

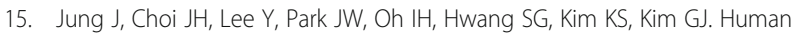
placenta-derived mesenchymal stem cells promote hepatic regeneration in CCl4 -injured rat liver model via increased autophagic mechanism. Stem Cells. 2013:31(8):1584-96.

16. Jung J, Moon JW, Choi JH, Lee YW, Park SH, Kim GJ. Epigenetic alterations of IL-6/STAT3 signaling by placental stem cells promote hepatic regeneration in a rat model with CCl4-induced liver injury. Int J Stem Cells. 2015;8(1):79-89.

17. Yu J, Hao G, Wang D, Liu J, Dong $X$, Sun $Y$, et al. Therapeutic effect and location of GFP-labeled placental mesenchymal stem cells on hepatic fibrosis in rats. Stem Cells Int. 2017;2017:1798260.

18. Rios P, Li X, Kohn M. Molecular mechanisms of the PRL phosphatases. FEBS J. 2013;280(2):505-24.

19. Bai $Y$, Luo Y, Liu S, Zhang L, Shen K, Dong Y, et al. PRL-1 protein promotes ERK1/2 and RhoA protein activation through a non-canonical interaction with the Src homology 3 domain of p115 Rho GTPase-activating protein. J Biol Chem. 2011;286(49):42316-24.

20. Luo Y, Liang F, Zhang ZY. PRL1 promotes cell migration and invasion by increasing MMP2 and MMP9 expression through Src and ERK1/2 pathways. Biochemistry. 2009;48(8):1838-46.

21. Nakashima M, Lazo JS. Phosphatase of regenerating liver-1 promotes cell migration and invasion and regulates filamentous actin dynamics. J Pharmacol Exp Ther. 2010;334(2):627-33.

22. Jiao Y, Ye DZ, Li Z, Teta-Bissett M, Peng Y, Taub R, Greenbaum LE, Kaestner $\mathrm{KH}$. Protein tyrosine phosphatase of liver regeneration-1 is required for normal timing of cell cycle progression during liver regeneration. Am J Physiol Gastrointest Liver Physiol. 2015;308(2):G85-91.

23. Kobayashi M, Chen S, Gao R, Bai Y, Zhang ZY, Liu Y. Phosphatase of regenerating liver in hematopoietic stem cells and hematological malignancies. Cell Cycle. 2014;13(18):2827-35.

24. Kobayashi M, Bai Y, Dong Y, Yu H, Chen S, Gao R, et al. PRL2/PTP4A2 phosphatase is important for hematopoietic stem cell self-renewal. Stem Cells. 2014;32(7):1956-67. 
25. Kim MJ, Shin KS, Jeon JH, Lee DR, Shim SH, Kim JK, Cha DH, Yoon TK, Kim GJ. Human chorionic-plate-derived mesenchymal stem cells and Wharton's jelly-derived mesenchymal stem cells: a comparative analysis of their potential as placenta-derived stem cells. Cell Tissue Res. 2011;346(1):53-64.

26. Kountouras J, Billing BH, Scheuer PJ. Prolonged bile duct obstruction: a new experimental model for cirrhosis in the rat. Br J Exp Pathol. 1984;65(3):305-11.

27. Lee MJ, Jung J, Na KH, Moon JS, Lee HJ, Kim JH, et al. Anti-fibrotic effect of chorionic plate-derived mesenchymal stem cells isolated from human placenta in a rat model of CCl (4)-injured liver: potential application to the treatment of hepatic diseases. J Cell Biochem. 2010;111(6):1453-63.

28. Madesh M, Hajnoczky G. VDAC-dependent permeabilization of the outer mitochondrial membrane by superoxide induces rapid and massive cytochrome c release. J Cell Biol. 2001;155(6):1003-15.

29. O'Brien KM. Mitochondrial biogenesis in cold-bodied fishes. J Exp Biol. 2011; 214(Pt 2):275-85

30. Eguchi A, Koyama Y, Wree A, Johnson CD, Nakamura R, Povero D, et al. Emricasan, a pan-caspase inhibitor, improves survival and portal hypertension in a murine model of common bile-duct ligation. J Mol Med (Berl). 2018;96(6):575-83.

31. Gazdic M, Arsenijevic A, Markovic BS, Volarevic A, Dimova I, Djonov V, Arsenijevic N, Stojkovic M, Volarevic V. Mesenchymal stem cell-dependent modulation of liver diseases. Int J Biol Sci. 2017:13(9):1109-17.

32. Fiore EJ, Mazzolini G, Aquino JB. Mesenchymal stem/stromal cells in liver fibrosis: recent findings, old/new caveats and future perspectives. Stem Cell Rev. 2015;11(4):586-97.

33. Jang YO, Kim YJ, Baik SK, Kim MY, Eom YW, Cho MY, et al. Histological improvement following administration of autologous bone marrow-derived mesenchymal stem cells for alcoholic cirrhosis: a pilot study. Liver Int. 2014; 34(1):33-41.

34. Eom YW, Shim KY, Baik SK. Mesenchymal stem cell therapy for liver fibrosis. Korean J Intern Med. 2015;30(5):580-9.

35. Cizkova D, Cubinkova V, Smolek T, Murgoci AN, Danko J, Vdoviakova K et al. Correction: Cizkova, D., et al. Localized intrathecal delivery of mesenchymal stromal cells conditioned media improves functional recovery in a rat model of contusive spinal cord injury. Int J Mol Sci. 2018;19:870. Int J Mol Sci 2018;19(7):1942.

36. Buckle M. Regulation of ATP hydrolase activity of the F0-F1 complex of ratliver mitochondria during early hepatic regeneration. FEBS Lett. 1986;209(2): 197-202.

37. Serviddio G, Pereda J, Pallardo FV, Carretero J, Borras C, Cutrin J, et al. Ursodeoxycholic acid protects against secondary biliary cirrhosis in rats by preventing mitochondrial oxidative stress. Hepatology. 2004;39(3):711-20.

38. Arduini A, Serviddio G, Escobar J, Tormos AM, Bellanti F, Vina J, Monsalve M, Sastre J. Mitochondrial biogenesis fails in secondary biliary cirrhosis in rats leading to mitochondrial DNA depletion and deletions. Am J Physiol Gastrointest Liver Physiol. 2011;301(1):G119-27.

39. Tiao MM, Lin TK, Wang PW, Chen JB, Liou CW. The role of mitochondria in cholestatic liver injury. Chang Gung Med J. 2009:32(4):346-53.

40. Yan W, Li D, Chen T, Tian G, Zhou P, Ju X. Umbilical cord MSCs reverse Dgalactose-induced hepatic mitochondrial dysfunction via activation of Nrf2/ HO-1 pathway. Biol Pharm Bull. 2017:40(8):1174-82.

41. El'chaninov AV, Volodina MA, Arutyunyan IV, Makarov AV, Tarasova NV, Kananykhina EY, et al. Effect of multipotent stromal cells on the function of cell mitochondria in regenerating liver. Bull Exp Biol Med. 2015;158(4):566-72.

\section{Publisher's Note}

Springer Nature remains neutral with regard to jurisdictional claims in published maps and institutional affiliations.

Ready to submit your research? Choose BMC and benefit from:
- fast, convenient online submission
- thorough peer review by experienced researchers in your field
- rapid publication on acceptance
- support for research data, including large and complex data types
- gold Open Access which fosters wider collaboration and increased citations
- maximum visibility for your research: over 100M website views per year
At BMC, research is always in progress.
Learn more biomedcentral.com/submissions

